\title{
DILEMAS DO AGRONEGÓCIO: AMPLIAR OU NÃO A COMERCIALIZAÇÃO DE GRÃOS?
}

\author{
Tatiane Bento da Costa* \\ tatiane.costa.bento@hotmail.com \\ Juliana Xavier de Castro* \\ xjuliana@hotmail.com \\ João Paulo Gomes Barbosa* \\ joaopaulo@propp.ufu.br \\ Edvalda Araujo Leal* \\ edvalda@facic.ufu.br \\ *Universidade Federal de Uberlândia
}

http://dx.doi.org/10.1590/1413.2311.054.62143

Recebido em 11/02/2016

Aprovado em 02/05/2017

Disponibilizado em 07/08/2017

Avaliado pelo sistema "double blind review"

Revista Eletrônica de Administração

Editoras-chefe: Andrea Oltramari e Maria Ceci Misoczky

ISSN 1413-2311 (versão "on line")

Editada pela Escola de Administração da Universidade Federal do Rio Grande do Sul

Periodicidade: Quadrimestral

Sistema requerido: Adobe Acrobat Reader

\section{RESUMO}

A empresa GRAN Agro, no final do ano de 2014, tinha como meta definir novas estratégias a serem adotadas na área de comercialização de grãos. Antônio Silveira, Chief Executive Officer (CEO), foi pressionado fortemente pelos acionistas da organização em uma reunião estratégica. Os mesmos cobraram do CEO melhores resultados financeiros, tendo em vista que eles desejam maiores lucros, incluindo o aumento das distribuições de dividendos, para que a empresa se torne mais atrativa aos investidores no mercado. Analisando então esse desafio e a trajetória de negócios da empresa, bem como pesquisando o cenário do mercado de agronegócios brasileiro e internacional, Antônio verificou que havia chegado o momento de a GRAN Agro ampliar sua atuação no mercado de grãos. Assim, ele optou por analisar a viabilidade de comercialização do milho, pois considerou que esse tenderia a se manter como excelente alternativa de produção no Brasil. Além disso, poderia ser aproveitada a infraestrutura que a empresa já possuía, existindo, ainda, a opção de exportação, dependendo das condições econômicas do cenário mundial, haja vista que o milho é um grão bastante consumido. O desafio do CEO é verificar a viabilidade da comercialização desse grão. Para isso, ele contará com o auxilio da diretora financeira e o diretor de operações, em conjunto com suas equipes, para analisar informações sobre o mercado do 'milho safrinha' em três principais estados brasileiros, envolvendo custos e despesas. O objetivo será analisar a viabilidade da escolha do mercado para adquirir o milho para a comercialização da GRAN Agro. Os diretores 
envolvidos deverão utilizar métodos quantitativos para analisar o mercado (estado) que trará melhores resultados.

Palavras-chave: Custos. Estatística. Métodos Quantitativos. Interdisciplinaridade.

\begin{abstract}
The company GRAN Agro, at the end of 2014, had as its goal to define new strategies to be adopted in the grain marketing area. Antonio Silveira, Chief Executive Officer (CEO), was strongly pressed by the organization's shareholders at a strategy meeting. They charged the CEO better financial results, considering that they want higher profits, including the increase in dividend distributions, so that the company becomes more attractive to investors in the market. Then analyzing this challenge and the company's business trajectory, as well as researching the scenario of the Brazilian and international agribusiness market, Antonio found that the time had come for the GRAN Agro expand its operations in the grain market. So he chose to analyze the feasibility of commercialization of corn, because it considered that this would tend to maintain an excellent alternative production in Brazil. Moreover, it could be taken advantage of the infrastructure that the company already had, and there also the export option, depending on economic conditions of the world stage, given that corn is a widely consumed grain. The challenge of the CEO is to check the feasibility of marketing of grain.

For this you will have the help of the chief financial officer and chief operating officer, together with their teams to analyze information on the market 'winter maize' in three main Brazilian states, involving costs and expenses. The aim will be to analyze the feasibility of choice of the market for corn for the commercialization of Agro GRAN. The directors involved should use quantitative methods to analyze the market (state) that will yield better results.
\end{abstract}

Keywords:Costs. Statistics. Quantitative Methods. Interdisciplinary.

\title{
RESUMEN
}

La empresa GRAN Agro, a finales de 2014, tenía como objetivo definir nuevas estrategias que se adoptarán en el área de comercialización de granos. Antonio Silveira, Director Ejecutivo (CEO), fue fuertemente presionado por los accionistas de la organización en una reunión de estrategia. Ellos pagan el director general mejores resultados financieros, teniendo en cuenta que ellos quieren mayores beneficios, entre ellos el aumento de la distribución de dividendos, por lo que la empresa se vuelve más atractivo para los inversores en el mercado. Luego de analizar este desafío y la trayectoria empresarial de la compañía, así como la investigación de la situación del mercado de la agroindustria brasileña e internacional, Antonio encontró que había llegado el tiempo para que el GRAN Agro expandir sus operaciones en el mercado de granos. Así que se optó por analizar la viabilidad de la comercialización de maíz, por considerar que esto tendería a mantener una excelente alternativa de producción en Brasil. Por otra parte, podría ser aprovechado la infraestructura que la empresa ya tenía, y también la opción de exportación, dependiendo de las condiciones económicas de la escena mundial, dado que el maíz es un grano de gran consumo. El reto del CEO es comprobar la viabilidad de comercialización de granos. Para ello, tendrá la ayuda del director financiero y director de operaciones, junto con sus equipos para analizar la información en el mercado maíz de invierno 'en tres principales estados brasileños, que implica costos y gastos. El objetivo será analizar la viabilidad de la opción del mercado para el maíz para la comercialización de Agro GRAN. Los directores involucrados deben utilizar métodos cuantitativos para analizar el mercado (estado) que producirá mejores resultados. 
Palabras clave: Costos. Estadísticas. Métodos cuantitativos. La interdisciplinariedad.

\section{Introdução}

O Grupo GRAN Holding é um dos mais sólidos grupos empresariais do Brasil, abarcando no grupo empresas que atuam em diversos setores da economia como: telecomunicações, serviços, aviação, segurança e agronegócios. A empresa foi fundada no ano 1929 e detém o controle da empresa GRAN Agro, fundada 49 anos mais tarde, sendo essa empresa o objeto de análise deste caso.

No final do ano de 2014, a empresa GRAN Agro tinha como meta definir novas estratégias a serem adotadas na área de comercialização de grãos. Antônio Silveira, Chief Executive Officer (CEO), foi pressionado fortemente pelos acionistas da organização em uma reunião estratégica. Os mesmos cobraram do CEO melhores resultados financeiros, tendo em vista que eles desejam maiores lucros, incluindo o aumento das distribuições de dividendos, para tornar a empresa mais atrativa aos investidores atuais, bem como aos potenciais investidores no mercado.

Analisando então esse desafio e a trajetória de negócios da empresa, e pesquisando o cenário do mercado de agronegócios brasileiro e internacional, Antônio verificou que havia chegado o momento de a GRAN Agro ampliar sua atuação no mercado de grãos, pois, desde o ano 1978, quando a subsidiária do Grupo GRAN iniciou as suas atividades, a empresa se concentrou no complexo de soja, e o mantém até o momento.

Para o CEO, os relacionamentos que a empresa possui com diversos tipos de clientes são parcerias sólidas, visto que a empresa ocupa no mercado posição de destaque como intermediária de grãos, tendo a empresa, então, condições de incluir em seu portfólio a comercialização de outro tipo de grão. Dentre as alternativas existentes, Antônio optou por analisar a viabilidade de comercialização do milho, pois considerou que esse tenderia a se manter como excelente alternativa de produção no Brasil. Além disso, poderia ser aproveitada a infraestrutura que a empresa já possuía.

Antônio estava preocupado com os novos rumos que a empresa poderia tomar, visto que as novas estratégias de comercialização poderiam afetar significativamente os resultados da empresa. Ele pensava nos colaboradores da empresa e seus familiares, aqueles que dependiam direta ou indiretamente do bom desempenho da empresa para manter seu emprego.

Assim, o CEO agendou uma reunião de urgência com a diretora financeira (Melissa Avelar), seu braço direito na gestão da empresa, e o diretor de operações (Sérgio Melo), 
responsável pela análise de mercado e comercialização de grãos. Antônio contará com o auxílio dos mesmos e suas respectivas equipes para analisarem informações sobre o mercado do milho safrinha (que seria na ocasião a próxima safra a ser colhida) em três principais estados brasileiros, envolvendo custos e despesas. O objetivo será analisar a viabilidade da escolha do mercado para adquirir o milho para a comercialização da GRAN Agro.

\section{0 setor de comercialização de commodity}

Commodity é um termo de língua inglesa (plural commodities) que significa mercadoria. Esse termo é utilizado em transações comerciais de produtos de origem primária nas bolsas de mercadorias, inclusive, no segmento de Mercadorias e Futuro da BM\&F da Bolsa de Valores de São Paulo - BOVESPA/SP.

O referido termo é utilizado como referência aos produtos de base em estado bruto (matérias-primas) ou com pequeno grau de industrialização, de qualidade quase uniforme, produzidos em grandes quantidades e por diferentes produtores. Esses produtos "in natura", cultivados, ou de extração mineral, podem ser estocados por determinado período sem perda significativa de qualidade.

O desafio da internacionalização se apresenta para as empresas na medida em que os mercados tornam-se cada vez próximos em virtude do aprimoramento e modernização dos modais de transportes que facilitam o escoamento de produtos. Assim, atuar dentro do próprio país, quando há demanda, pode ser mais lucrativo se bem administrado. Mas é possível pensar também que, como a demanda mundial é alta, então, se o mercado interno não absorver toda produção, existe mercado no exterior com demanda para comprar o excedente da produção desse grão, podendo a lucratividade, porém, ser inferior.

O Brasil possui relevância mundial no fornecimento de commodities para outros países, destacando-se na exportação de grãos, como a soja (tanto o grão, quanto o farelo) e o milho. Segundo a Companhia Nacional de Abastecimento (CONAB, 2012) o momento de pressão inflacionária aquece a demanda pelo milho e pela soja no mercado externo.

Em 2014, segundo dados do Ministério do Desenvolvimento, Indústria e Comércio Exterior (MDIC, 2014), o Brasil exportou o milho no ano de 2014 num montante de R\$ 1.703.656.933 bilhões, correspondendo a um volume de 8.385.208 milhões de toneladas. As exportações alcançaram 60 países, representando a consolidação do Brasil como um dos principais exportadores dessa commodity no mundo. Os números mostram o potencial de movimentação desse grão, pois a demanda ao redor do mundo é bastante alta. 
Tal fato traz relevância para diversos setores da área contábil, controladoria e área comercial dentro de uma empresa que tem como atividade principal a comercialização do produto milho. É extremamente importante conhecer o mercado e, principalmente, as ferramentas que trazem poder de predição às decisões que esteja em sintonia com a velocidade com a qual as informações acontecem o responsável por essa área de levantamentos de informações estratégicas é o gerente de operações, Sr. Sérgio Melo.

Em relação à produção do milho, percebe-se a relevância do consumo mundial desse grão. A produção e o consumo mundial de milho vêm aumentando com constância, desde 1960 até o ano 2013cresce com pequenas exceções, evidenciando o mercado em expansão e a alta demanda anual pelo produto. Em 2013, a demanda mundial girava em torno de, aproximadamente, 850 mil toneladas, segundo o USDA (CONAB, 2012).

O milho é relevante pelas suas diversas possibilidades de utilização, podendo ser fonte de alimentação para consumo humano final ou intermediário, sendo seus derivados também bastante utilizados, como: insumos na indústria de alimentos, amidos, xaropes, de rações, adesivos, entre outras possibilidades (DUARTE; GARCIA; MIRANDA, 2011). No Brasil, o produto é muito utilizado, bem como suas diversas variações e derivados.

A produção do milho no Brasil se concentra, com cerca de 90\%, nas regiões: Sudeste $(19,13 \%)$, Centro-Oeste (30,18\%) e Sul (40,76\%). Nos anos 2010/2011, aumentou a participação do milho safrinha na composição da produção total do milho no país, proporcionada, em sua maioria, pelos estados que compõem o Centro-oeste e o estado do Paraná. Para a produção 2010/2011, os estados do Paraná, Mato Grosso e Goiás, juntos, tiveram a responsabilidade de produzir $77,11 \%$ da produção nacional (DUARTE, GARCIA E MIRANDA, 2011).

No Gráfico 1, é possível analisar e concluir que o Brasil é um importante produtor mundial da commodity milho, sendo o terceiro maior produtor mundial dessa cultura.

Gráfico 1 - Produção de milho nos anos 2013/14 e a respectiva projeção para produção com colheita nas safras de 2014/2015 (em milhões de toneladas). 


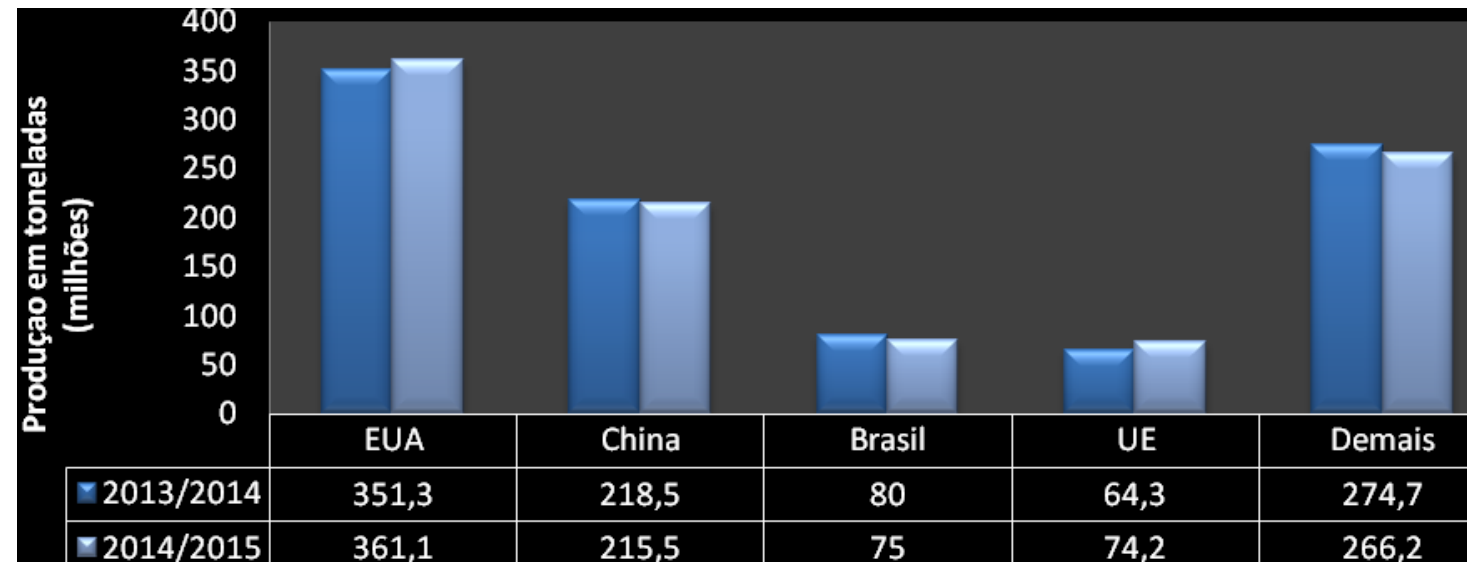

Fonte: Adaptado de DEAGRO/FIESP (2015).

Sob essa perspectiva, o Brasil tem relevância junto a outros países produtores, como China e EUA, ocupando a terceira posição no mercado mundial, Considerando a projeção para o ano de 2015, ainda que ocorra uma retração na produção dessa commodity no Brasil, o país continuará ocupando a mesma colocação, sem possibilidades de ser ultrapassado pela UE.

\section{Histórico da empresa GRAN Agro}

A GRAN Agro é uma companhia brasileira de capital fechado que atua no mercado de soja desde 1978. A empresa possui uma infraestrutura física com 30 armazéns localizados estrategicamente próximos às áreas de origens (compra) de grãos e duas unidades de processamento de soja. Além da produção, do processamento e da comercialização de soja nos mercados interno e externo, a companhia tem como produtos-âncora, de fabricação própria, o óleo de soja XYZ, líder de vendas no estado de Minas Gerais, e o farelo de soja, denominado Boi Gordo. O mix de produtos alimentícios voltado ao varejo contempla o azeite de oliva, o extrato e molho de tomate, todos com a marca ABC.

No Triângulo Mineiro, a unidade Uberlândia/MG, com 406 mil m², também sede administrativa da GRAN Agro, é um dos mais avançados complexos industriais do país para (processamento) esmagamento, refino e envase de óleo de soja, com uma capacidade de armazenar 180 mil toneladas de grãos e de esmagamento de 1,8 mil toneladas de soja ao dia. Região geograficamente privilegiada, o centro do Brasil oferece extraordinária malha viária, recursos naturais e tecnológicos, além de mão de obra qualificada.

Equipada com tecnologia de ponta, a unidade em Porto Franco, localizada no estado do Maranhão, ocupando uma área de $200 \mathrm{mil} \mathrm{m}^{2}$, possui localização favorável com convergência de modais rodoviários para ferroviários interligados ao terminal de Itaqui. Essa localização 
viabiliza a compra da soja produzida no MAPITOPA - região que abrange os estados de Maranhão, Piauí, Tocantins, Pará e Nordeste do estado do Mato Grosso, considerada uma nova fronteira agrícola do país - e também o escoamento de produtos direcionados ao mercado externo. Sua capacidade atual é de 60 mil toneladas de armazenamento de grãos e 1,6 mil toneladas de esmagamento ao dia.

Há uma forte tendência para que a GRAN Agro possa iniciar sua atuação no mercado de milho. Desde 1978, quando a subsidiária do Grupo GRAN iniciou as atividades, os negócios se concentram no complexo da cultura do grão soja. Caso opte pela inserção dessa nova atividade, a intenção da empresa será atender, principalmente, à demanda interna. A expectativa é chegar ao montante de 100 mil toneladas movimentadas ainda no ano de 2015. Até 2020, dentro do plano de expansão projetada, o milho deve representar $20 \%$ do total movimentado, chegando a um milhão de toneladas.

Em 2013, a GRAN Agro faturou R\$ 1,8 bilhão, 12,5\% a mais que no ano anterior, quando a receita ficou em $\mathrm{R} \$ 1,6$ bilhão. A receita da subsidiária - que também está no ramo de alimentos e rações - representou $45 \%$ do total do Grupo GRAN, que atua ainda em áreas como aviação, segurança, tecnologia, telecomunicações e turismo. No Quadro 1, apresentam-se os principais pontos históricos da empresa GRAN Agro desde sua fundação.

Quadro 1: Principais pontos históricos da empresa GRAN Agro.

1978 - Comendador Fortes Silva diversifica os negócios do Grupo GRAN com aquisição da empresa Fujiwara, na cidade de Uberlândia/MG, que atuava no segmento de algodão, com capacidade de esmagamento de 400 toneladas ao dia.

1982 - Expansão da capacidade de esmagamento para 600 t/dia.

1985 - Substitui o esmagamento de algodão pelo esmagamento de soja.

1989 - Nova expansão aumenta a capacidade de esmagamento para 1,2 mil ton./dia e dá início às atividades de refinação de 200 ton/dia de óleo com envasamento automático.

1996 - Capacidade de esmague diário sobe para 1,5 mil toneladas.

1999 - Primeira empresa da América Latina no segmento de alimentos a obter simultaneamente as certificações de excelência em gestão ambiental (ISO 14001) e qualidade (ISO 9002).

2000 - Capacidade de esmagamento atinge 1,8 mil toneladas ao dia.

2001 - Investimentos em expansão e aprimoramento do processo de refinaria permitem ampliar a produção para 400 ton/dia de óleo.

2006 - O óleo de soja passa a ser envasado em embalagem PET, aquisição de silo na cidade de Coromandel/MG, com capacidade de armazenamento de 50 mil toneladas, e inauguração da 
Unidade Porto Franco/MA, com capacidade de esmagamento de 1,6 mil toneladas de soja ao dia e estrutura para armazenamento de 60 mil toneladas.

2007 - Expansões da capacidade de armazenamento no Estado do Maranhão, com os silos em Chapadinha (18 mil toneladas) e Ilha de Balsas (36 mil toneladas).

2008 - Para reforçar o posicionamento de "ser uma empresa nacional com atuação regionalizada", o óleo de soja XYZ passa a se chamar Minas, e o mix de produtos com a marca é ampliado com o lançamento de mais quatro itens: azeite de oliva, óleo composto, extrato e molho de tomate. Aquisição de armazém em Campos Lindos/TO com capacidade de armazenamento de 50 mil toneladas.

2009 - Dentro da estratégia de reestruturação de todas as marcas do Grupo GRAN, a então ABC INCO adota o nome de GRAN Agro.

2011 - Ampliação das operações no Norte/Nordeste, com a inauguração da refinaria na Unidade Porto Franco/MA, com investimentos de R \$ 50 milhões.

2012 - Devido à entrada no mercado Norte/Nordeste, a marca ABC de Minas passa a se chamar $\mathrm{ABC}$.

2013 - Substituição da matriz energética de Porto Franco de combustível fóssil para uma fonte renovável.

Fonte: Algar Agro (2013).

\section{O Dilema: Ampliação do portfólio de culturas processadas pela GRAN Agro}

Em sua sala, na sede da empresa GRAN Agro, o Sr. Antônio, CEO da GRAN Agro, refletia sobre estratégias para alcançar o aumento nos resultados em sua empresa (novas commodites, como o milho, novos mercados, etc...). Ele deveria apresentar o planejamento na reunião com os acionistas, que aconteceria daí a duas semanas na cidade de São Paulo. Naquele momento, ele sabia que a expectativa dos acionistas era grande em relação ao que seria apresentado, por isso precisaria ser analítico e assertivo quanto ao que iria propor.

O Sr. Antônio verificou o relógio e deu-se conta de que havia chegado a hora da reunião agendada com a diretora financeira (Melissa Avelar) e o gerente de operações (Sérgio Melo). Durante a reunião, ele explicou aos dois a exigência dos acionistas sobre as novas estratégias para o aumento dos resultados da empresa.

O CEO comentou que analisou a trajetória de negócios da empresa e pesquisou o mercado de agronegócios brasileiro e internacional e verificou que havia chegado o momento da GRAN Agro ampliar sua atuação no mercado de grãos, porque, desde 1978, quando a subsidiária do Grupo iniciou suas atividades, concentravam-se somente no complexo da soja. 
Para ele, com o relacionamento que já tinham estabelecido com os clientes, a empresa apresentava perfeitas condições de ampliar o seu portfólio de comercialização de grãos, e, dentre as alternativas que existiam, optou-se pelo milho, pois considerou que esse grão tenderia a se manter como excelente alternativa de produção estável no Brasil.

A empresa comprava e processava 1,6 milhão de toneladas de soja em suas unidades localizadas em Minas Gerais, no Norte e no Nordeste do Brasil. Em Minas, a empresa detém uma fatia de $28 \%$ do mercado de soja e, na região do MATOPIBA, área da divisa dos estados do Maranhão, Tocantins, Piauí e Bahia, a sua participação chega a 25\%.

Como não havia planos de ampliar a estrutura física da empresa naquele primeiro momento, e a intenção era atender, principalmente, o mercado interno, deveriam verificar quais estados brasileiros seriam os mais viáveis para a concretização da comercialização do milho.

Assim, durante a reunião, Antônio reforçou alguns aspectos: “Temos a incumbência de escolher os estados brasileiros de atuação para a compra do milho e tomar uma decisão rápida e assertiva, pois em duas semanas terei uma reunião com os acionistas da empresa e preciso apresentar o planejamento para ampliação do portfólio de produtos comercializados com vistas a alcançar melhores resultados financeiros para a empresa”.

OCEO ainda solicitou aos diretores uma análise completa e consistente, pois ele precisava convencer os acionistas a aceitarem a comercialização do milho, visto que, sem a aprovação, o projeto não seria operacionalizado e, consequentemente, seria necessário buscar novas alternativas para aumentar o resultado (lucro) da GRAN Agro.

Antônio também solicitou o auxílio da diretora financeira e do gerente de operações para analisar os aspectos operacionais e financeiros dessa oportunidade de diversificação de investimento, ou seja, comercializar a cultura do milho e definir sua viabilidade econômica no portfólio de investimentos do Grupo GRAN.

Considerando esse dilema, era necessário identificar e analisar informações detalhadas sobre o mercado do milho, como: quais seriam os principais concorrentes, os entraves burocráticos para entrar no ramo e todo o contexto atrelado aos custos de produção do milho de cada estado, bem como a forma de escoação da produção, pois, quanto maiores os custos de operação, menor a rentabilidade do negócio e sua viabilidade econômica. O CEO solicitou que todas as análises fossem pautadas em assertividade, utilizando-se métodos estatísticos para auxiliar nas tomadas de decisão e otimizar os acertos nas previsões.

\section{Análise do novo projeto: processamento e comercialização do Milho}


Após ouvir o relato do Sr. Antônio, Melissa apresentou suas ponderações sobre como o projeto deveria ser analisado e quais os próximos passos. A princípio, a diretora financeira ressaltou a necessidade de se analisarem os dados históricos das safras de milho disponibilizados pelo site da CONAB - Companhia Nacional de Abastecimento, pois, para ela, era relevante conhecer o mercado no qual se pretendia atuar a fim de obter dados que possibilitem o uso de técnicas e ferramentas com poder de predição.

Melissa sugeriu a utilização de métodos quantitativos focados, principalmente, na análise de custos, salientando que, ao utilizar informações quantitativas, como a análise de bancos de dados, os gestores poderiam aumentar a precisão e reduzir a subjetividade no momento de decisão.

Outra sugestão da diretora financeira pautou-se na utilização de informações qualitativas a fim de obter informações como os principais concorrentes, os potenciais entrantes, os clientes (nacionais e internacionais), a previsão de consumo, o comportamento de custos e as séries históricas de formação de preço, estoques, população, demanda dentre outros.

Assim, a diretora financeira e o gerente de operações, em conjunto com suas equipes de colaboradores, ficaram responsáveis por analisar os relatórios de custos e despesas de três principais estados brasileiros que atuam no mercado do milho, inclusive, com o apoio de testes estatísticos para a análise da viabilidade da escolha do mercado para aquisição do milho com a finalidade de comercialização por parte da GRAN Agro.

\section{0 que considerar para a avaliação do novo projeto?}

Logo após a reunião com o CEO, Melissa e Sérgio reuniram os colaboradores (analistas) dos dois setores, a fim de apresentaram a situação informada pelo Sr. Antônio, solicitando o auxílio dos mesmos para as análises econômico-financeiras e de mercado. Para tanto, apresentaram as seguintes questões: é viável o processamento e comércio do milho pela GRAN Agro? Quais os estados deverão ser escolhidos para a realização dos investimentos com o milho?

Melissa havia feito uma pesquisa prévia e descobriu que Goiás, Mato Grosso e Paraná, juntos, são os estados responsáveis por $77 \%$ da produção do milho do Brasil. Na reunião, ficou decidido que a equipe irá aprofundar a análise nesses três estados, já que serão as principais fontes para a compra do milho. A diretora informou que, considerando o fim do ano de 2014, iriam analisar os relatórios do 'milho safrinha', que é a safra extemporânea atual, a qual está em 
andamento. Ela ainda informou que, no sítio da CONAB, são disponibilizados dados referentes ao milho safrinha desses estados de forma completa em um período histórico.

Melissa e Sérgio levantaram alguns dados e relatórios que foram disponibilizados aos analistas do departamento financeiro e de operações. Os primeiros dados estão disponíveis no Anexo I - Tabela 2 a descrição das variáveis pesquisadas nos relatórios do CONAB. Os gestores orientaram que os dados coletados na CONAB são disponibilizados com periodicidade anual, podendo ocorreram intervalos de períodos diferenciados, dependendo da disposição das variáveis do milho 'Safrinha'. O principal relatório para pesquisa é o "Custos de produção: culturas da seca da série histórica da cultura do milho do período de 1997 a 2014". Em uma análise temporal prévia, Melissa verificou que o período disponível por estado é o seguinte: Goiás, período de 2005 a 2014 (10 anos); Mato Grosso, de 1997 a 2014 (18 anos); e o estado do Paraná, de 1999 a 2014 (16 anos).

As Tabelas 2 a 12, constantes nos Anexos I e II são as tabelas organizadas por Melissa e Sérgio referente à análise descritiva das variáveis selecionadas para a análise da cultura do milho, à correlação linear de Pearson e o Teste t de amostras independentes, considerando os estados pesquisados (GO, PR e MT).

\section{Desafio do Caso}

A partir das informações apresentadas no caso e Anexos disponibilizados, os alunos atuarão como analistas do setor financeiro e do setor de operações têm o desafio de responder os questionamentos a seguir, com embasamento teórico sobre o tema e assertividade, utilizando-se de métodos estatísticos aplicados nos dados dos relatórios sobre as safras de milho disponibilizadas no site da CONAB (www.conab.gov.br/).

\section{Questões a serem resolvidas:}

1) Como se dá o comportamento dos custos e das despesas em GO, PR e MT? Existe diferença perceptível nas respectivas composições desses estados? Explique.

1.a) Analisar o comportamento das variáveis nos três estados (GO, PR e MT) de acordo com a análise descritiva (Tabelas 3 e 4). Levando em consideração somente a Variável Aluguel de Máquinas e seu respectivo coeficiente de variação. É possível perceber algum ponto fraco em algum estado? Qual o estado com menores valores de custos e despesas? Explique. 
1.b) Na Tabela 5 a maior associação negativa linear foi apresentada entre as variáveis produtividade e manutenção de máquinas como pode ser interpretada essa situação na prática? Ainda analisando a Tabela 5 qual a maior associação positiva linear e qual a interpretação que pode ser feita referente tal associação? Na Tabela 6 quais as maiores associações lineares negativas e positivas?

1.c) As médias diferentes de custos e despesas em cada estado (GO, PR e MT) são em decorrência do acaso ou são estatisticamente diferentes? Responda baseando-se nas tabelas disponibilizadas do Teste T (Tabelas 7 a 12).

2) Quais estados, entre PR, MT ou GO, possuem logísticas mais favoráveis para a escoação da produção de acordo com a infraestrutura física que a empresa já possui? Levando em consideração o caso relatado e seus conhecimentos sobre transportes logísticos.

3) Em qual estado a GRAN Agro deve iniciar seu negócio no ramo do milho? Levando em consideração todo o contexto, quais as melhores possibilidades de geração de receitas com menores despesas e custos? Importante respaldar as respostas nas análises feitas nas questões anteriores.

\section{REFERÊNCIAS}

ALGAR AGRO. Empresa. 2013. Disponível em:

<http://www.algaragro.com.br/algaragro.qps/Ref/PAIA-6XZ62B>. Acesso em: 24 abr. 2015.

BUSSAB, W. O; MORETIN, P. A. Estatística Básica. 4. ed. São Paulo: Saraiva, 2003.

CONAB. Companhia Nacional de Abastecimento. Custos de produção: culturas da seca da série histórica da cultura do milho do período de 1997 a 2014. 2014.

CONAB. Companhia Nacional de Abastecimento. Metodologia de cálculo de custo de produção da CONAB. 2012.

CONAB. Companhia Nacional de Abastecimento. Séries históricas de área plantada, produtividade e produção, relativas às safras 1976/77 a 2014/15 de grãos. Disponível em: <http://www.conab.gov.br/conteudos.php?a=1252\&t=2>. Acesso em: 14 jul. 2017.

DNIT - Departamento Nacional de Infraestrutura de Transportes. Modais. 2002. Disponível em:<http://www.dnit.gov.br/>. Acesso em: 30 jun. 2015. 
DUARTE, J.O.; GARCIA, J. C.; MIRANDA, R. A. Cultivo do Milho: Economia da Produção.7. Ed. set. 2011. Disponível em:

<http://www.cnpms.embrapa.br/publicacoes/milho_7_ed/economia.html>. Acesso em: 14 jul. 2017.

FGV. Fundação Getúlio Vargas. Índices Gerais de Preços IGPM. 2015. Disponível em:<http://portalibre.fgv.br/main.jsp?lumChannelId=402880811D8E34B9011D92B6160B0D7 D >. Acesso em: 01 abr. 2015.

HAIR JR, J. F. et. al. Análise multivariada de dados. 6.ed. Porto Alegre. Bookman, 2009.

LIRA, S. A. Análise de correlação: abordagem teórica e de construção dos coeficientes com aplicações.209 f. Dissertação (Mestrado) - Universidade Federal do Paraná, Curitiba, 2004.

MDIC (Ministério do Desenvolvimento, Indústria e Comércio - Sistema Alice Web). Sistema de Análise das Informações de comércio exterior via internet do MDIC. 2014. Disponível em:<http://aliceweb.mdic.gov.br/>. Acesso em: 13 maio 2015.

PALMER, C. L. (ed.). Navigating Among the Disciplines:The Library and Interdisciplinary Inquiry. Urbana-champaign library large escale digitization Library Trends Magazine. Project. 2007.

SILVA, L. H. O.; PINTO, F. N. P. Interdisciplinaridade: As práticas possíveis. Revista Querubim, [s.1.], Ano 5,2009.

TURNER, R. H. The many faces of American sociology:A discipline in search of identity. In: Divided knowledges: Across disciplines, across cultures. Newbury Park, CA: Sage, 1991.59-85 p.

\section{ANEXO 1 (Tabelas - Disponibilizar o Anexo I e II aos alunos/participantes)}

Tabela 2. Descrição das variáveis selecionadas para análise.

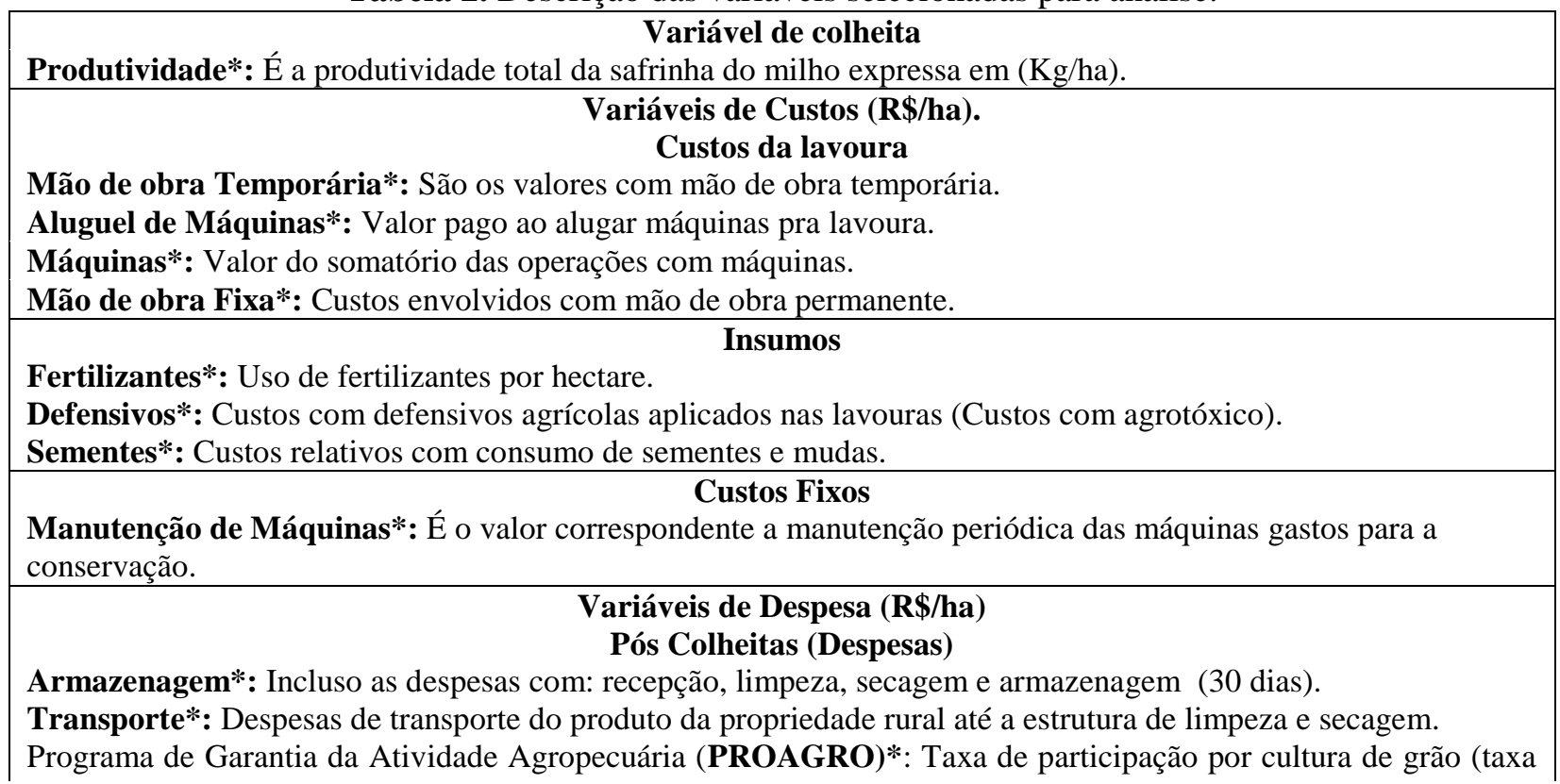


adicional) o valor é pago ao Banco Central do Brasil (BACEN) para obter assistência técnica.

Assistência Técnica: São os valores de assistência técnica.

\section{Juros de Despesa Financeira}

Juros de despesas Financeiras*: Os juros incidentes sobre os recursos tomados emprestados para investir nos custeios da lavoura.

\section{Depreciações}

Depreciação*: É o somatório das despesas que referem à depreciação de instalações/ benfeitorias, máquinas e implementos.

*: Valores das respectivas séries foram deflacionadas de acordo o Índice Geral de Preços do Mercado (IGPM) de acordo com a série histórica disponível no site da Fundação Getúlio Vargas (FGV, 2015). Fonte: CONAB, 2012; $2014 ; 2015$.

Tabela 3. Análise Descritiva Geral de todas variáveis

\begin{tabular}{c|c|c|c|c|c}
\hline Variáveis & Média & $\begin{array}{c}\text { Desvio } \\
\text { padrão }\end{array}$ & Mínimo & Máximo & $\begin{array}{c}\text { Coeficiente de } \\
\text { Variação(\%) }\end{array}$ \\
\hline Transporte & 86,76 & 24,95 & 40,22 & 153,76 & $29 \%$ \\
\hline Armazenagem & 98,00 & 37,78 & 52,65 & 212,63 & $39 \%$ \\
\hline PROAGRO & 24,77 & 17,44 & 0,00 & 50,05 & $70 \%$ \\
\hline Assistência Técnica & 16,17 & 7,32 & 0,00 & 29,25 & $45 \%$ \\
\hline Juros de despesas Financeiras & 37,56 & 10,11 & 20,66 & 61,90 & $27 \%$ \\
\hline Depreciação & 138,27 & 47,59 & 56,58 & 310,85 & $34 \%$ \\
\hline Manutenção de Máquinas & 35,19 & 11,88 & 2,66 & 56,04 & $34 \%$ \\
\hline Produtividade & 3,85 & 1,28 & 1,07 & 6,13 & $33 \%$ \\
\hline Máquinas & 165,42 & 50,17 & 74,60 & 316,67 & $30 \%$ \\
\hline Aluguel de Máquinas & 33,25 & 64,95 & 0,00 & 279,90 & $195 \%$ \\
\hline Mão de obra Temporária & 8,53 & 5,17 & 0,00 & 31,55 & $61 \%$ \\
\hline Mão de obra Fixa & 36,90 & 29,98 & 11,48 & 168,70 & $81 \%$ \\
\hline Sementes & 216,41 & 66,48 & 130,12 & 421,20 & $31 \%$ \\
\hline Fertilizantes & 356,51 & 105,88 & 229,12 & 691,74 & $30 \%$ \\
\hline Defensivos & 141,43 & 51,45 & 55,86 & 284,19 & $36 \%$ \\
\hline
\end{tabular}

*C.V.: Coeficiente de Variação (\%) Fonte: Elaborado pelos autores.

Tabela 4. Análise Descritiva onde foram analisadas as variáveis por estado: PR, GO, MT.

\begin{tabular}{|c|c|c|c|c|c|c|c|c|c|c|c|c|c|c|c|}
\hline \multirow[b]{2}{*}{ Variáveis } & \multicolumn{5}{|c|}{ Descritiva: Estado Goiás (n: 10) } & \multicolumn{5}{|c|}{ Descritiva: Mato Grosso (n: 18) } & \multicolumn{5}{|c|}{ Descritiva: Paraná (n: 16) } \\
\hline & Média & $\begin{array}{c}\text { Desvi } \\
\text { o } \\
\text { padrã } \\
\text { o }\end{array}$ & Mín. & Máx. & $\begin{array}{l}* \mathrm{C} . \mathrm{V} . \\
(\%)\end{array}$ & $\begin{array}{l}\text { Médi } \\
\text { a }\end{array}$ & $\begin{array}{c}\text { Desvi } \\
\text { o } \\
\text { padrão }\end{array}$ & Mín. & Máx. & $\begin{array}{l}{ }^{*} \mathrm{C} . \mathrm{V} \\
.(\%)\end{array}$ & $\begin{array}{l}\text { Médi } \\
\text { a }\end{array}$ & $\begin{array}{c}\text { Desvi } \\
\text { o } \\
\text { padrão }\end{array}$ & Mín. & Máx. & $\begin{array}{l}{ }^{*} \text { C.V } \\
(\%)\end{array}$ \\
\hline $\begin{array}{l}\text { Mão de Obra } \\
\text { Fixa }\end{array}$ & 37,2 & 13,2 & 18,2 & 70,3 & $35 \%$ & 27,7 & 7,5 & 11,5 & 38,5 & $27 \%$ & 47,1 & 46,8 & 16,8 & 168,7 & $99 \%$ \\
\hline Sementes & 232,6 & 61,8 & 181,9 & 380,0 & $27 \%$ & 208,9 & 72,4 & 141,1 & 421,2 & $35 \%$ & 214,8 & 64,7 & 130,1 & 323,5 & $30 \%$ \\
\hline Fertilizantes & 350,3 & 137,6 & 229,1 & 668,0 & $39 \%$ & 406,7 & 106,1 & 263,9 & 691,7 & $26 \%$ & 303,9 & 45,0 & 232,6 & 375,2 & $15 \%$ \\
\hline Defensivos & 107,9 & 67,2 & 55,9 & 284,2 & $62 \%$ & 154,6 & 48,1 & 77,9 & 258,3 & $31 \%$ & 147,6 & 35,5 & 95,3 & 210,4 & $24 \%$ \\
\hline $\begin{array}{l}\text { Manutenção } \\
\text { de máquinas }\end{array}$ & 32,6 & 7,4 & 20,5 & 42,8 & $23 \%$ & 40,2 & 16,1 & 2,7 & 56,0 & $40 \%$ & 31,1 & 5,2 & 24,2 & 40,2 & $17 \%$ \\
\hline $\begin{array}{c}\text { Produtividad } \\
\text { e }\end{array}$ & 4,9 & 0,9 & 3,5 & 6,1 & $19 \%$ & 3,6 & 1,3 & 1,5 & 5,8 & $35 \%$ & 3,5 & 1,2 & 1,1 & 5,4 & $34 \%$ \\
\hline Máquinas & 184,9 & 80,1 & 85,1 & 316,7 & $43 \%$ & 163,6 & 42,7 & 74,6 & 234,0 & $26 \%$ & 155,2 & 30,6 & 106,2 & 211,6 & $20 \%$ \\
\hline
\end{tabular}




\begin{tabular}{c|c|c|c|c|c|c|c|c|c|c|c|c|c|c|c}
$\begin{array}{c}\text { Aluguel de } \\
\text { Máquinas }\end{array}$ & 29,3 & 88,1 & 0,0 & 279,9 & $301 \%$ & 0,0 & 0,0 & 0,0 & 0,0 & $0 \%$ & 73,2 & 66,4 & 5,0 & 181,4 & $91 \%$ \\
\hline $\begin{array}{c}\text { Mão Obra } \\
\text { Temporária }\end{array}$ & 11,2 & 7,9 & 0,0 & 31,5 & $71 \%$ & 7,8 & 4,6 & 0,0 & 12,7 & $59 \%$ & 7,7 & 2,9 & 3,9 & 11,7 & $38 \%$ \\
\hline Transporte & 104,0 & 27,8 & 72,2 & 154 & $27 \%$ & 90,3 & 26,0 & 40,2 & 150,0 & $29 \%$ & 72,0 & 10,6 & 53,6 & 90,9 & $15 \%$ \\
\hline $\begin{array}{c}\text { Armazenage } \\
\text { m }\end{array}$ & 95,8 & 26,9 & 64,8 & 135 & $28 \%$ & 109,6 & 48,5 & 65,0 & 212,6 & $44 \%$ & 86,4 & 26,2 & 52,7 & 131 & $30 \%$ \\
\hline $\begin{array}{c}\text { PROAGRO } \\
\text { PROA, }\end{array}$ & 20,2 & 17,6 & 0,0 & 37,1 & $87 \%$ & 28,7 & 16,3 & 0,0 & 50,0 & $57 \%$ & 23,2 & 18,7 & 0,0 & 39,8 & $81 \%$ \\
\hline $\begin{array}{c}\text { Assistência } \\
\text { Técnica }\end{array}$ & 13,3 & 10,0 & 0,0 & 29,3 & $75 \%$ & 16,3 & 8,1 & 0,0 & 28,5 & $50 \%$ & 17,8 & 3,2 & 8,8 & 20,4 & $18 \%$ \\
\hline $\begin{array}{c}\text { Juros de } \\
\text { despesas } \\
\text { financeiras }\end{array}$ & 30,9 & 5,9 & 20,7 & 37,7 & $19 \%$ & 33,6 & 5,5 & 24,1 & 43,1 & $16 \%$ & 46,2 & 10,5 & 30,0 & 61,9 & $23 \%$ \\
\hline \begin{tabular}{c} 
Depreciação \\
\hline
\end{tabular} & 136,2 & 42,4 & 72,4 & 180 & $31 \%$ & 159,8 & 59,4 & 56,6 & 310,9 & $37 \%$ & 115,3 & 16,9 & 92,1 & 148 & $15 \%$ \\
\hline
\end{tabular}

*C.V.: Coeficiente de Variação (\%) Fonte: Elaborado pelos autores.

Tabela 5. Análise de correlação linear de Pearson das variáveis de custos e a variável produtividade.

\begin{tabular}{|c|c|c|c|c|c|c|c|c|c|}
\hline \multicolumn{10}{|c|}{ Matrizes: Correlação de Pearson e seus respectivos p-valores. } \\
\hline Variáveis & 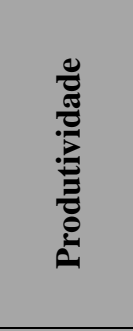 & 胥 & 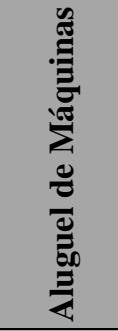 & 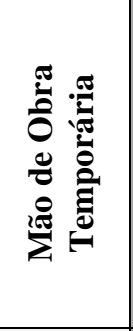 & 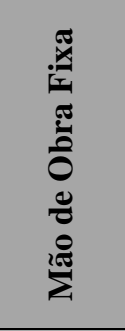 & 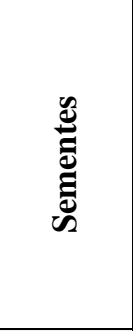 & 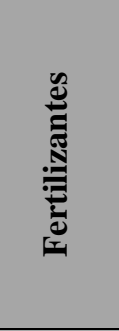 & 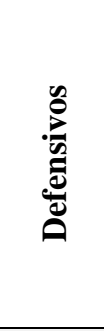 & 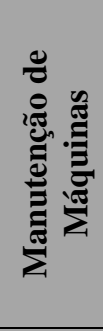 \\
\hline Produtividade & 1 & 0,005 & 0,308 & 0,337 & 0,034 & 0,049 & 0,088 & 0,141 & 0,000 \\
\hline Máquinas & $-0,414^{* *}$ & 1 & 0,068 & 0,068 & 0,076 & 0,255 & 0,588 & 0,877 & 0,000 \\
\hline $\begin{array}{l}\text { Aluguel de } \\
\text { Máquinas }\end{array}$ & 0,157 & $-0,278$ & 1 & 0,208 & 0,004 & 0,166 & 0,017 & 0,777 & 0,066 \\
\hline $\begin{array}{l}\text { Mão de Obra } \\
\text { Temporária }\end{array}$ & $-0,148$ & 0,278 & $-0,194$ & 1 & 0,914 & 0,246 & 0,037 & 0,006 & 0,013 \\
\hline $\begin{array}{c}\text { Mão de Obra } \\
\text { Fixa } \\
\end{array}$ & $0,321^{*}$ & $-0,271$ & $0,422^{* *}$ & 0,017 & 1 & 0,036 & 0,037 & 0,644 & 0,194 \\
\hline Sementes & $0,299^{*}$ & $-0,175$ & $-0,212$ & $-0,179$ & $-0,317^{*}$ & 1 & 0,002 & 0,771 & 0,001 \\
\hline Fertilizantes & 0,260 & $-0,084$ & $-0,357^{*}$ & $-0,315^{*}$ & $-0,315^{*}$ & $0,459^{* *}$ & 1 & 0,021 & 0,578 \\
\hline Defensivos & $-0,225$ & $-0,024$ & 0,044 & $-0,409^{* *}$ & $-0,072$ & $-0,045$ & $0,346^{*}$ & 1 & 0,532 \\
\hline $\begin{array}{l}\text { Manutenção } \\
\text { de Máquinas }\end{array}$ & $-0,578^{* *}$ & $0,666^{* *}$ & $-0,280$ & $0,372^{*}$ & $-0,200$ & $-0,502^{* *}$ & $-0,086$ & 0,097 & 1 \\
\hline
\end{tabular}

Obs: Abaixo da diagonal principal são os valores respectivos aos coeficientes de correlação linear de Pearson e acima da diagonal principal está o respectivo p-valor.

Fonte: Elaborado pelos autores.

Tabela 6. Análise de correlação linear de Pearson das variáveis de despesas com a variável produtividade. 


\begin{tabular}{|c|c|c|c|c|c|c|c|}
\hline Variáveis & 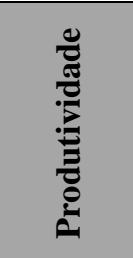 & 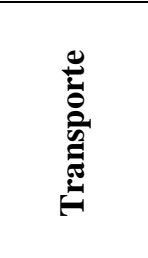 & 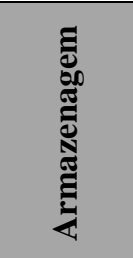 & 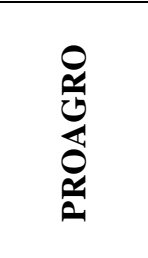 & 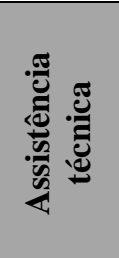 & 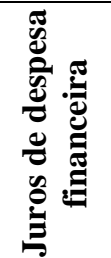 & 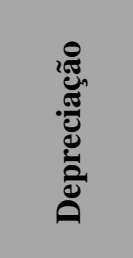 \\
\hline Produtividade & 1 & $1.20 \mathrm{E}-06$ & 0,000 & 9,9E-06 & 0,039 & 0,007 & 0,501 \\
\hline Transporte & $0,658^{* *}$ & 1 & 0,001 & 0,006 & 0,569 & 0,005 & 0,225 \\
\hline Armazenagem & $0,494^{* *}$ & $0,473^{* *}$ & 1 & 4.00E-09 & 0,002 & 0,113 & 0,660 \\
\hline PROAGRO & $-0,613$ & $-0,402^{* * *}$ & $-0,752^{* * *}$ & 1 & 0,000 & 0,061 & 0,051 \\
\hline Assistência técnica & $-0,312^{*}$ & $-0,0882$ & $-0,445^{* *}$ & $0,533^{* *}$ & 1 & 0,111 & $7,8 \mathrm{E}-06$ \\
\hline $\begin{array}{l}\text { Juros de despesa } \\
\text { financeira }\end{array}$ & $-0,397^{* *}$ & $-0,413^{* *}$ & $-0,242$ & 0,284 & 0.243 & 1 & 0,111 \\
\hline Depreciação & $-0,104$ & 0,186 & $-0,068$ & 0,295 & $0,618^{* *}$ & -0.243 & 1 \\
\hline
\end{tabular}

Fonte: Elaborado pelos autores.

\section{ANEXO II (Tabelas - Disponibilizar o Anexo I e II aos alunos/participantes)}

Tabela 7. Teste $\mathrm{T}$ de amostras independentes entre os estados do GO e PR com as variáveis de produtividade e de custos.

\begin{tabular}{|c|c|c|c|c|c|c|c|c|c|c|}
\hline \multicolumn{11}{|c|}{ Teste T de Amostras Independentes entre GO e PR } \\
\hline \multirow{3}{*}{\multicolumn{2}{|c|}{ Variáveis de Custos }} & \multicolumn{2}{|c|}{$\begin{array}{c}\text { Teste de } \\
\text { Levene para } \\
\text { igualdade de } \\
\text { variações }\end{array}$} & \multicolumn{7}{|c|}{ Teste t para Igualdade de Médias } \\
\hline & & \multirow{2}{*}{$\mathbf{F}$} & \multirow{2}{*}{$\begin{array}{l}\text { Valo } \\
\mathbf{r}-\mathbf{p}\end{array}$} & \multirow[t]{2}{*}{$\mathbf{t}$} & \multirow{2}{*}{$\begin{array}{c}\text { Grau de } \\
\text { Liberdad } \\
\text { e }\end{array}$} & \multirow{2}{*}{$\begin{array}{c}\text { Valor }-\mathbf{p} \\
(2 \\
\text { extremidade } \\
\mathbf{s})\end{array}$} & \multirow{2}{*}{$\begin{array}{l}\text { Diferenç } \\
\text { a de } \\
\text { Média }\end{array}$} & \multirow{2}{*}{$\begin{array}{c}\text { Erro } \\
\text { padrão } \\
\text { de } \\
\text { diferenç } \\
\text { a }\end{array}$} & \multicolumn{2}{|c|}{$\begin{array}{l}\text { 95\% Intervalo de } \\
\text { confiança da } \\
\text { diferença }\end{array}$} \\
\hline & & & & & & & & & $\begin{array}{c}\text { Inferio } \\
\mathbf{r}\end{array}$ & $\begin{array}{c}\text { Superio } \\
\mathbf{r}\end{array}$ \\
\hline \multirow[b]{2}{*}{$\begin{array}{c}\text { Produtividad } \\
\mathrm{e}\end{array}$} & $\begin{array}{c}\text { Variaçõe } \\
\text { s iguais } \\
\text { assumida } \\
\text { s }\end{array}$ & 2,813 & 0,106 & 3,445 & 24 & 0,002 & 1,500 & 0,435 & 0,601 & 2,399 \\
\hline & $\begin{array}{c}\text { Variaçõe } \\
\text { s iguais } \\
\text { não } \\
\text { assumida } \\
\text { s }\end{array}$ & & & 3,770 & 23,785 & 0,001 & 1,500 & 0,398 & 0,678 & 2,322 \\
\hline \multirow[b]{2}{*}{ Máquinas } & $\begin{array}{c}\text { Variaçõe } \\
\mathrm{s} \text { iguais } \\
\text { assumida } \\
\mathrm{s}\end{array}$ & $\begin{array}{c}14,91 \\
6\end{array}$ & 0,001 & 1,348 & 24 & 0,190 & 29,775 & 22,095 & $-15,826$ & 75,376 \\
\hline & $\begin{array}{c}\text { Variaçõe } \\
\mathrm{s} \text { iguais } \\
\text { não } \\
\text { assumida } \\
\text { s }\end{array}$ & & & 1,123 & 10,654 & 0,286 & 29,775 & 26,525 & $-28,839$ & 88,389 \\
\hline \multirow[t]{2}{*}{$\begin{array}{l}\text { Aluguel de } \\
\text { Máquinas }\end{array}$} & $\begin{array}{c}\text { Variaçõe } \\
\text { s iguais } \\
\text { assumida } \\
\text { s }\end{array}$ & 0,194 & 0,663 & $\begin{array}{c}- \\
1,439\end{array}$ & 24 & 0,163 & $-43,663$ & 30,343 & $\begin{array}{c}- \\
106,287\end{array}$ & 18,962 \\
\hline & $\begin{array}{l}\text { Variaçõe } \\
\text { s iguais }\end{array}$ & & & $\begin{array}{c}- \\
1,347 \\
\end{array}$ & 15,374 & 0,198 & $-43,663$ & 32,422 & $\begin{array}{c}- \\
112,622 \\
\end{array}$ & 25,297 \\
\hline
\end{tabular}




\begin{tabular}{|c|c|c|c|c|c|c|c|c|c|c|}
\hline & $\begin{array}{c}\text { não } \\
\text { assumida } \\
\text { s }\end{array}$ & & & & & & & & & \\
\hline \multirow{2}{*}{$\begin{array}{c}\text { Mão de } \\
\text { Obra } \\
\text { Temporária }\end{array}$} & $\begin{array}{c}\text { Variaçõe } \\
\text { s iguais } \\
\text { assumida } \\
\text { s }\end{array}$ & 0,864 & 0,362 & 1,568 & 24 & 0,130 & 3,450 & 2,200 & $-1,090$ & 7,990 \\
\hline & $\begin{array}{l}\text { Variaçõe } \\
\text { s iguais } \\
\text { não } \\
\text { assumida } \\
\text { s }\end{array}$ & & & 1,301 & 10,534 & 0,221 & 3,450 & 2,651 & $-2,417$ & 9,317 \\
\hline \multirow[b]{2}{*}{$\begin{array}{l}\text { Mão de } \\
\text { Obra Fixa }\end{array}$} & $\begin{array}{c}\text { Variaçõe } \\
\text { s iguais } \\
\text { assumida } \\
\text { s }\end{array}$ & 3,550 & 0,072 & $\begin{array}{c}- \\
0,657\end{array}$ & 24 & 0,518 & $-10,050$ & 15,301 & $-41,629$ & 21,529 \\
\hline & $\begin{array}{l}\text { Variaçõe } \\
\text { s iguais } \\
\text { não } \\
\text { assumida } \\
\text { s }\end{array}$ & & & $\begin{array}{c}- \\
0,808\end{array}$ & 18,518 & 0,430 & $-10,050$ & 12,445 & $-36,143$ & 16,043 \\
\hline \multirow[b]{2}{*}{ Sementes } & $\begin{array}{c}\text { Variaçõe } \\
\text { s iguais } \\
\text { assumida } \\
\text { s }\end{array}$ & 0,415 & 0,525 & 0,697 & 24 & 0,492 & 17,850 & 25,597 & $-34,980$ & 70,680 \\
\hline & $\begin{array}{l}\text { Variaçõe } \\
\text { s iguais } \\
\text { não } \\
\text { assumida } \\
\text { s }\end{array}$ & & & 0,704 & 19,870 & 0,489 & 17,850 & 25,345 & $-35,041$ & 70,741 \\
\hline \multirow[b]{2}{*}{ Fertilizantes } & $\begin{array}{c}\text { Variaçõe } \\
\text { s iguais } \\
\text { assumida } \\
\text { s }\end{array}$ & 9,952 & 0,004 & 1,258 & 24 & 0,221 & 46,363 & 36,861 & $-29,716$ & 122,441 \\
\hline & $\begin{array}{c}\text { Variaçõe } \\
\text { s iguais } \\
\text { não } \\
\text { assumida } \\
\text { s } \\
\end{array}$ & & & 1,032 & 10,212 & 0,326 & 46,363 & 44,939 & $-53,487$ & 146,212 \\
\hline \multirow[b]{2}{*}{ Defensivos } & $\begin{array}{c}\text { Variaçõe } \\
\text { s iguais } \\
\text { assumida } \\
\text { s }\end{array}$ & 0,980 & 0,332 & $\begin{array}{c}- \\
1,977\end{array}$ & 24 & 0,060 & $-39,663$ & 20,057 & $-81,059$ & 1,734 \\
\hline & $\begin{array}{l}\text { Variaçõe } \\
\text { s iguais } \\
\text { não } \\
\text { assumida } \\
\text { s }\end{array}$ & & & $\begin{array}{c}- \\
1,724\end{array}$ & 12,193 & 0,110 & $-39,663$ & 23,003 & $-89,694$ & 10,369 \\
\hline \multirow{2}{*}{$\begin{array}{l}\text { Manutenção } \\
\text { de Máquinas }\end{array}$} & $\begin{array}{c}\text { Variaçõe } \\
\text { s iguais } \\
\text { assumida } \\
\text { s }\end{array}$ & 0,895 & 0,353 & 0,594 & 24 & 0,558 & 1,475 & 2,482 & $-3,648$ & 6,598 \\
\hline & $\begin{array}{l}\text { Variaçõe } \\
\text { s iguais } \\
\text { não } \\
\text { assumida } \\
\text { s }\end{array}$ & & & 0,551 & 14,937 & 0,590 & 1,475 & 2,675 & $-4,229$ & 7,179 \\
\hline
\end{tabular}

Fonte: Elaborado pelos autores. 
Tabela 8. Teste T de amostras independentes entre os estados do GO e MT com as variáveis de produtividade e de custos.

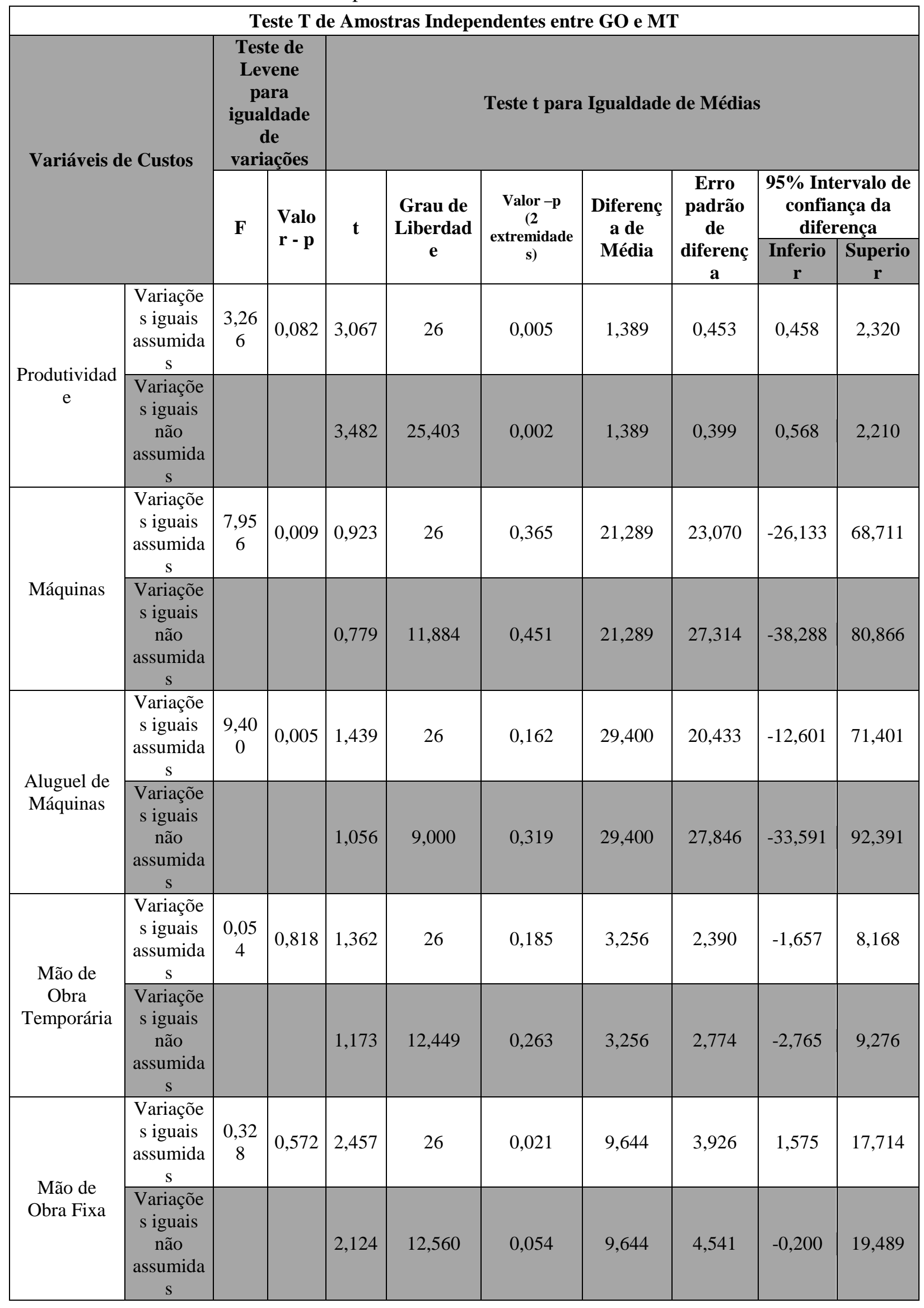




\begin{tabular}{|c|c|c|c|c|c|c|c|c|c|c|}
\hline \multirow[b]{2}{*}{ Sementes } & $\begin{array}{c}\text { Variaçõe } \\
\text { s iguais } \\
\text { assumida } \\
\text { s }\end{array}$ & $\begin{array}{c}0,22 \\
1\end{array}$ & 0,642 & 0,874 & 26 & 0,390 & 23,767 & 27,189 & $-32,121$ & 79,654 \\
\hline & $\begin{array}{c}\text { Variaçõe } \\
\text { s iguais } \\
\text { não } \\
\text { assumida } \\
\text { s }\end{array}$ & & & 0,916 & 21,362 & 0,370 & 23,767 & 25,960 & $-30,164$ & 77,697 \\
\hline \multirow[b]{2}{*}{ Fertilizantes } & $\begin{array}{c}\text { Variaçõe } \\
\text { s iguais } \\
\text { assumida } \\
\text { s }\end{array}$ & $\begin{array}{c}0,98 \\
5\end{array}$ & 0,330 & $\begin{array}{c}- \\
1,210\end{array}$ & 26 & 0,237 & $-56,311$ & 46,529 & $\begin{array}{c}- \\
151,952\end{array}$ & 39,330 \\
\hline & $\begin{array}{c}\text { Variaçõe } \\
\text { s iguais } \\
\text { não } \\
\text { assumida } \\
\text { s }\end{array}$ & & & 1,122 & 15,060 & 0,279 & $-56,311$ & 50,190 & 163,251 & 50,628 \\
\hline \multirow[b]{2}{*}{ Defensivos } & $\begin{array}{c}\text { Variaçõe } \\
\text { s iguais } \\
\text { assumida } \\
\text { s }\end{array}$ & $\begin{array}{c}0,04 \\
2\end{array}$ & 0,840 & 2,133 & 26 & 0,043 & $-46,600$ & 21,844 & $-91,502$ & $-1,698$ \\
\hline & $\begin{array}{l}\text { Variaçõe } \\
\text { s iguais } \\
\text { não } \\
\text { assumida } \\
\text { s }\end{array}$ & & & $\begin{array}{c}- \\
1,937\end{array}$ & 14,238 & 0,073 & $-46,600$ & 24,055 & $-98,113$ & 4,913 \\
\hline \multirow{2}{*}{$\begin{array}{l}\text { Manutenção } \\
\text { de Máquinas }\end{array}$} & $\begin{array}{c}\text { Variaçõe } \\
\text { s iguais } \\
\text { assumida } \\
\text { s }\end{array}$ & $\begin{array}{c}3,37 \\
4\end{array}$ & 0,078 & $\begin{array}{c}- \\
1,419\end{array}$ & 26 & 0,168 & $-7,622$ & 5,370 & $-18,660$ & 3,416 \\
\hline & $\begin{array}{l}\text { Variaçõe } \\
\text { s iguais } \\
\text { não } \\
\text { assumida } \\
\text { s }\end{array}$ & & & $\begin{array}{c}- \\
1,724\end{array}$ & 25,436 & 0,097 & $-7,622$ & 4,421 & $-16,720$ & 1,476 \\
\hline
\end{tabular}

Fonte: Elaborado pelos autores.

Tabela 9. Teste $\mathrm{T}$ de amostras independentes entre os estados do MT e PR com as variáveis de produtividade e de custos.

\begin{tabular}{|c|c|c|c|c|c|c|c|c|c|c|}
\hline \multicolumn{11}{|c|}{ Teste de amostras independentes entre MT e PR } \\
\hline \multirow{3}{*}{\multicolumn{2}{|c|}{ Variáveis de Custos }} & \multicolumn{2}{|c|}{\begin{tabular}{|c|} 
Teste de \\
Levene para \\
igualdade de \\
variações \\
\end{tabular}} & \multicolumn{7}{|c|}{ Teste t para Igualdade de Médias } \\
\hline & & \multirow[t]{2}{*}{$\mathbf{F}$} & \multirow{2}{*}{$\begin{array}{l}\text { Valo } \\
\mathbf{r}-\mathbf{p}\end{array}$} & \multirow[t]{2}{*}{$\mathbf{t}$} & \multirow{2}{*}{$\begin{array}{c}\text { Grau de } \\
\text { Liberdad } \\
\text { e }\end{array}$} & \multirow{2}{*}{$\begin{array}{c}\text { Valor }-p \\
(2 \\
\text { extremidade } \\
\text { s) }\end{array}$} & \multirow{2}{*}{$\begin{array}{c}\text { Diferenç } \\
\text { a de } \\
\text { Média }\end{array}$} & \multirow{2}{*}{\begin{tabular}{|c|} 
Erro \\
padrão \\
de \\
diferenç \\
a \\
\end{tabular}} & \multicolumn{2}{|c|}{$\begin{array}{l}\text { 95\% Intervalo de } \\
\text { confiança da } \\
\text { diferença }\end{array}$} \\
\hline & & & & & & & & & $\begin{array}{c}\text { Inferio } \\
\mathbf{r}\end{array}$ & $\begin{array}{c}\text { Superio } \\
\mathbf{r}\end{array}$ \\
\hline \multirow[b]{2}{*}{$\begin{array}{c}\text { Produtividad } \\
\mathrm{e}\end{array}$} & $\begin{array}{c}\text { Variaçõe } \\
\text { s iguais } \\
\text { assumida } \\
\text { s }\end{array}$ & 0,059 & 0,810 & 0,258 & 32 & 0,7980 & 0,111 & 0,431 & $-0,766$ & 0,988 \\
\hline & $\begin{array}{l}\text { Variaçõe } \\
\text { s iguais } \\
\text { não } \\
\text { assumida } \\
\text { s }\end{array}$ & & & 0,259 & 31,891 & 0,797 & 0,111 & 0,429 & $-0,763$ & 0,985 \\
\hline
\end{tabular}




\begin{tabular}{|c|c|c|c|c|c|c|c|c|c|c|}
\hline \multirow[b]{2}{*}{ Máquinas } & $\begin{array}{c}\text { Variaçõe } \\
\mathrm{s} \text { iguais } \\
\text { assumida } \\
\mathrm{s}\end{array}$ & 0,642 & 0,429 & 0,659 & 32 & 0,515 & 8,486 & 12,877 & $-17,744$ & 34,716 \\
\hline & $\begin{array}{c}\text { Variaçõe } \\
\mathrm{s} \text { iguais } \\
\text { não } \\
\text { assumida } \\
\mathrm{s}\end{array}$ & & & 0,672 & 30,719 & 0,507 & 8,486 & 12,630 & $-17,282$ & 34,254 \\
\hline \multirow{2}{*}{$\begin{array}{l}\text { Aluguel de } \\
\text { Máquinas }\end{array}$} & $\begin{array}{c}\text { Variaçõe } \\
\mathrm{s} \text { iguais } \\
\text { assumida } \\
\mathrm{s}\end{array}$ & $\begin{array}{c}84,20 \\
3\end{array}$ & 0,000 & $\begin{array}{c}- \\
4,675\end{array}$ & 32 & 0,000 & $-73,063$ & 15,627 & $\begin{array}{c}- \\
104,894\end{array}$ & $-41,231$ \\
\hline & $\begin{array}{c}\text { Variaçõe } \\
\mathrm{s} \text { iguais } \\
\text { não } \\
\text { assumida } \\
\text { s } \\
\end{array}$ & & & $\begin{array}{c}- \\
4,399\end{array}$ & 15,000 & 0,001 & $-73,063$ & 16,608 & $\begin{array}{c}- \\
108,461\end{array}$ & $-37,664$ \\
\hline \multirow{2}{*}{$\begin{array}{c}\text { Mão de } \\
\text { Obra } \\
\text { Temporária }\end{array}$} & $\begin{array}{c}\text { Variaçõe } \\
\mathrm{s} \text { iguais } \\
\text { assumida } \\
\mathrm{s}\end{array}$ & 2,637 & 0,114 & 0,143 & 32 & 0,887 & 0,194 & 1,361 & $-2,577$ & 2,966 \\
\hline & $\begin{array}{c}\text { Variaçõe } \\
\mathrm{s} \text { iguais } \\
\text { não } \\
\text { assumida } \\
\text { s } \\
\end{array}$ & & & 0,147 & 29,075 & 0,884 & 0,194 & 1,326 & $-2,517$ & 2,906 \\
\hline \multirow{2}{*}{$\begin{array}{l}\text { Mão de } \\
\text { Obra Fixa }\end{array}$} & $\begin{array}{c}\text { Variaçõe } \\
\mathrm{s} \text { iguais } \\
\text { assumida } \\
\mathrm{s}\end{array}$ & 7,728 & 0,009 & $\begin{array}{c}- \\
1,757\end{array}$ & 32 & 0,088 & $-19,694$ & 11,207 & $-42,521$ & 3,133 \\
\hline & $\begin{array}{c}\text { Variaçõe } \\
\text { s iguais } \\
\text { não } \\
\text { assumida } \\
\text { s } \\
\end{array}$ & & & $\begin{array}{c}- \\
1,659\end{array}$ & 15,728 & 0,117 & $-19,694$ & 11,871 & $-44,895$ & 5,507 \\
\hline \multirow[b]{2}{*}{ Sementes } & $\begin{array}{c}\text { Variaçõe } \\
\mathrm{s} \text { iguais } \\
\text { assumida } \\
\mathrm{s}\end{array}$ & 0,003 & 0,954 & $0,-$ & 32 & 0,804 & $-5,917$ & 23,638 & $-54,065$ & 42,231 \\
\hline & $\begin{array}{c}\text { Variaçõe } \\
\mathrm{s} \text { iguais } \\
\text { não } \\
\text { assumida } \\
\mathrm{s}\end{array}$ & & & $0, \overline{-} 52$ & 31,999 & 0,803 & $-5,917$ & 23,472 & $-53,728$ & 41,895 \\
\hline \multirow[b]{2}{*}{ Fertilizantes } & $\begin{array}{c}\text { Variaçõe } \\
\mathrm{s} \text { iguais } \\
\text { assumida } \\
\mathrm{s}\end{array}$ & 4,010 & 0,054 & 3,590 & 32 & 0,001 & 102,674 & 28,601 & 44,416 & 160,931 \\
\hline & $\begin{array}{c}\text { Variaçõe } \\
\text { s iguais } \\
\text { não } \\
\text { assumida } \\
\text { s }\end{array}$ & & & 3,745 & 23,466 & 0,001 & 102,674 & 27,419 & 46,015 & 159,332 \\
\hline \multirow[t]{2}{*}{ Defensivos } & $\begin{array}{c}\text { Variaçõe } \\
\mathrm{s} \text { iguais } \\
\text { assumida } \\
\mathrm{s}\end{array}$ & 1,735 & 0,197 & 0,474 & 32 & 0,639 & 6,938 & 14,638 & $-22,879$ & 36,754 \\
\hline & $\begin{array}{c}\text { Variaçõe } \\
\text { s iguais }\end{array}$ & & & 0,482 & 31,025 & 0,633 & 6,938 & 14,379 & $-22,388$ & 36,263 \\
\hline
\end{tabular}




\begin{tabular}{|c|c|c|c|c|c|c|c|c|c|c|}
\hline & $\begin{array}{c}\text { não } \\
\text { assumida } \\
\text { s }\end{array}$ & & & & & & & & & \\
\hline \multirow{2}{*}{$\begin{array}{l}\text { Manutenção } \\
\text { de Máquinas }\end{array}$} & $\begin{array}{c}\text { Variaçõe } \\
\text { s iguais } \\
\text { assumida } \\
\text { s }\end{array}$ & 8,045 & 0,008 & 2,171 & 32 & 0,037 & 9,097 & 4,191 & 0,561 & 17,634 \\
\hline & $\begin{array}{l}\text { Variaçõe } \\
\text { s iguais } \\
\text { não } \\
\text { assumida } \\
\text { s }\end{array}$ & & & 2,279 & 21,148 & 0,033 & 9,097 & 3,993 & 0,798 & 17,397 \\
\hline
\end{tabular}

Fonte: Elaborado pelos autores.

Tabela 10. Teste $\mathrm{T}$ de amostras independentes entre os estados do GO e MT com as variáveis de produtividade e de despesas.

\begin{tabular}{|c|c|c|c|c|c|c|c|c|c|c|}
\hline \multicolumn{11}{|c|}{ Teste de amostras independentes entre GO e MT } \\
\hline \multirow{3}{*}{\multicolumn{2}{|c|}{ Variáveis de Despesa }} & \multicolumn{2}{|c|}{$\begin{array}{c}\text { Teste de } \\
\text { Levene } \\
\text { para } \\
\text { igualdade } \\
\text { de } \\
\text { variações } \\
\end{array}$} & \multicolumn{7}{|c|}{ Teste t para Igualdade de Médias } \\
\hline & & \multirow[t]{2}{*}{$\mathbf{F}$} & \multirow{2}{*}{$\begin{array}{l}\text { Valo } \\
\mathbf{r}-\mathbf{p}\end{array}$} & \multirow[t]{2}{*}{$\mathbf{t}$} & \multirow{2}{*}{$\begin{array}{c}\text { Grau de } \\
\text { Liberdad } \\
\text { e }\end{array}$} & \multirow{2}{*}{$\begin{array}{l}\text { Valor }-\mathbf{p} \\
(2 \\
\text { extremidade } \\
\mathbf{s})\end{array}$} & \multirow{2}{*}{$\begin{array}{l}\text { Diferenç } \\
\text { a de } \\
\text { Média }\end{array}$} & \multirow{2}{*}{$\begin{array}{c}\text { Erro } \\
\text { padrão } \\
\text { de } \\
\text { diferenç } \\
\text { a }\end{array}$} & \multicolumn{2}{|c|}{$\begin{array}{l}95 \% \text { Intervalo } \\
\text { de confiança da } \\
\text { diferença }\end{array}$} \\
\hline & & & & & & & & & $\begin{array}{c}\text { Inferio } \\
\mathbf{r} \\
\end{array}$ & $\begin{array}{c}\text { Superio } \\
\mathbf{r}\end{array}$ \\
\hline \multirow[b]{2}{*}{$\begin{array}{c}\text { Produtividad } \\
\text { e }\end{array}$} & $\begin{array}{l}\text { Variaçõe } \\
\text { s iguais } \\
\text { assumida } \\
\text { s }\end{array}$ & $\begin{array}{c}3,26 \\
6\end{array}$ & 0,082 & 3,067 & 26 & 0,005 & 1,389 & 0,453 & 0,458 & 2,320 \\
\hline & $\begin{array}{l}\text { Variaçõe } \\
\text { s iguais } \\
\text { não } \\
\text { assumida } \\
\text { s }\end{array}$ & & & 3,482 & 25,403 & 0,002 & 1,389 & 0,399 & 0,568 & 2,210 \\
\hline \multirow[b]{2}{*}{ Transporte } & $\begin{array}{l}\text { Variaçõe } \\
\text { s iguais } \\
\text { assumida } \\
\text { s }\end{array}$ & $\begin{array}{c}0,22 \\
7\end{array}$ & 0,638 & 1,281 & 26 & 0,212 & 13,456 & 10,507 & $-8,141$ & 35,053 \\
\hline & $\begin{array}{c}\text { Variaçõe } \\
\text { s iguais } \\
\text { não } \\
\text { assumida } \\
\text { s } \\
\end{array}$ & & & 1,254 & 17,594 & 0,226 & 13,456 & 10,732 & $-9,129$ & 36,040 \\
\hline \multirow{2}{*}{$\begin{array}{l}\text { Armazenage } \\
\mathrm{m}\end{array}$} & $\begin{array}{l}\text { Variaçõe } \\
\text { s iguais } \\
\text { assumida } \\
\text { s }\end{array}$ & $\begin{array}{c}1,82 \\
9\end{array}$ & 0,188 & $\begin{array}{c}- \\
0,831\end{array}$ & 26 & 0,414 & $-13,867$ & 16,686 & $-48,164$ & 20,431 \\
\hline & $\begin{array}{l}\text { Variaçõe } \\
\text { s iguais } \\
\text { não } \\
\text { assumida } \\
\text { s } \\
\end{array}$ & & & - & 25,994 & 0,339 & $-13,867$ & 14,235 & $-43,127$ & 15,393 \\
\hline PROAGRO & $\begin{array}{c}\text { Variaçõe } \\
\text { s iguais } \\
\text { assumida } \\
\text { s }\end{array}$ & $\begin{array}{c}1,05 \\
1\end{array}$ & 0,315 & $\begin{array}{c}- \\
1,298\end{array}$ & 26 & 0,206 & $-8,567$ & 6,600 & $-22,133$ & 5,000 \\
\hline
\end{tabular}




\begin{tabular}{|c|c|c|c|c|c|c|c|c|c|c|}
\hline & $\begin{array}{l}\text { Variaçõe } \\
\text { s iguais } \\
\text { não } \\
\text { assumida } \\
\text { s }\end{array}$ & & & $\begin{array}{c}- \\
1,271\end{array}$ & 17,585 & 0,220 & $-8,567$ & 6,743 & $-22,756$ & 5,623 \\
\hline \multirow{2}{*}{$\begin{array}{l}\text { Assistência } \\
\text { Técnica }\end{array}$} & $\begin{array}{c}\text { Variaçõe } \\
\text { s iguais } \\
\text { assumida } \\
\text { s }\end{array}$ & $\begin{array}{c}1,22 \\
6\end{array}$ & 0,278 & $\begin{array}{c}- \\
0,808\end{array}$ & 26 & 0,426 & $-2,822$ & 3,491 & $-9,999$ & 4,355 \\
\hline & $\begin{array}{l}\text { Variaçõe } \\
\text { s iguais } \\
\text { não } \\
\text { assumida } \\
\text { s }\end{array}$ & & & $-\overline{761}$ & 15,750 & 0,458 & $-2,822$ & 3,706 & $-10,689$ & 5,045 \\
\hline \multirow{2}{*}{$\begin{array}{c}\text { Juros de } \\
\text { Despesas } \\
\text { Financeiras }\end{array}$} & $\begin{array}{c}\text { Variaçõe } \\
\text { s iguais } \\
\text { assumida } \\
\text { s }\end{array}$ & $\begin{array}{c}0,09 \\
2\end{array}$ & 0,763 & $1, \overline{158}$ & 26 & 0,258 & $-2,556$ & 2,207 & $-7,093$ & 1,982 \\
\hline & $\begin{array}{l}\text { Variaçõe } \\
\text { s iguais } \\
\text { não } \\
\text { assumida } \\
\text { s }\end{array}$ & & & $\begin{array}{c}- \\
1,131\end{array}$ & 17,470 & 0,273 & $-2,556$ & 2,260 & $-7,314$ & 2,203 \\
\hline \multirow[b]{2}{*}{ Depreciação } & $\begin{array}{c}\text { Variaçõe } \\
\text { s iguais } \\
\text { assumida } \\
\text { s } \\
\end{array}$ & $\begin{array}{c}0,01 \\
3\end{array}$ & 0,909 & $\begin{array}{c}- \\
1,112\end{array}$ & 26 & 0,276 & $-23,733$ & 21,346 & $-67,610$ & 20,143 \\
\hline & $\begin{array}{l}\text { Variaçõe } \\
\text { s iguais } \\
\text { não } \\
\text { assumida } \\
\text { s }\end{array}$ & & & $\stackrel{-}{1,225}$ & 24,148 & 0,233 & $-23,733$ & 19,379 & $-63,718$ & 16,251 \\
\hline
\end{tabular}

Fonte: Elaborado pelos autores.

Tabela 11. Teste $\mathrm{T}$ de amostras independentes entre os estados do GO e PR com as variáveis de produtividade e de despesas.

\begin{tabular}{|c|c|c|c|c|c|c|c|c|c|c|}
\hline \multicolumn{11}{|c|}{ Teste de amostras independentes entre GO e PR } \\
\hline \multirow{3}{*}{\multicolumn{2}{|c|}{ Variáveis de Despesa }} & \multicolumn{2}{|c|}{$\begin{array}{c}\text { Teste de } \\
\text { Levene para } \\
\text { igualdade de } \\
\text { variações }\end{array}$} & \multicolumn{7}{|c|}{ Teste t para Igualdade de Médias } \\
\hline & & \multirow[t]{2}{*}{$\mathbf{F}$} & \multirow{2}{*}{$\begin{array}{l}\text { Valo } \\
\mathbf{r}-\mathbf{p}\end{array}$} & \multirow[t]{2}{*}{$\mathbf{t}$} & \multirow{2}{*}{$\begin{array}{c}\text { Grau de } \\
\text { Liberdad } \\
\text { e }\end{array}$} & \multirow{2}{*}{$\begin{array}{c}\text { Valor }-p \\
(2 \\
\text { extremidade } \\
\mathbf{s})\end{array}$} & \multirow{2}{*}{$\begin{array}{c}\text { Diferenç } \\
\text { a de } \\
\text { Média }\end{array}$} & \multirow{2}{*}{$\begin{array}{c}\text { Erro } \\
\text { padrão } \\
\text { de } \\
\text { diferenç } \\
\text { a } \\
\end{array}$} & \multicolumn{2}{|c|}{$\begin{array}{l}95 \% \text { Intervalo } \\
\text { de confiança da } \\
\text { diferença }\end{array}$} \\
\hline & & & & & & & & & $\begin{array}{c}\text { Inferio } \\
\mathbf{r}\end{array}$ & $\begin{array}{c}\text { Superio } \\
\mathbf{r}\end{array}$ \\
\hline \multirow[b]{2}{*}{$\begin{array}{c}\text { Produtividad } \\
\mathrm{e}\end{array}$} & $\begin{array}{c}\text { Variaçõe } \\
\text { s iguais } \\
\text { assumida } \\
\text { s }\end{array}$ & 2,813 & 0,106 & 3,445 & 24 & 0,002 & 1,500 & 0,435 & 0,601 & 2,399 \\
\hline & $\begin{array}{c}\text { Variaçõe } \\
\text { s iguais } \\
\text { não } \\
\text { assumida } \\
\text { s }\end{array}$ & & & 3,770 & 23,785 & 0,001 & 1,500 & 0,398 & 0,678 & 2,322 \\
\hline Transporte & $\begin{array}{c}\text { Variaçõe } \\
\text { s iguais } \\
\text { assumida } \\
\text { s }\end{array}$ & $\begin{array}{c}15,56 \\
4\end{array}$ & 0,001 & 4,169 & 24 & 0,000 & 31,900 & 7,652 & 16,106 & 47,694 \\
\hline
\end{tabular}




\begin{tabular}{|c|c|c|c|c|c|c|c|c|c|c|}
\hline & $\begin{array}{c}\text { Variaçõe } \\
\text { s iguais } \\
\text { não } \\
\text { assumida } \\
\text { s }\end{array}$ & & & 3,468 & 10,614 & 0,006 & 31,900 & 9,199 & 11,562 & 52,238 \\
\hline \multirow[b]{2}{*}{$\begin{array}{c}\text { Armazenage } \\
\mathrm{m}\end{array}$} & $\begin{array}{c}\text { Variaçõe } \\
\text { s iguais } \\
\text { assumida } \\
\text { s }\end{array}$ & 0,086 & 0,771 & 0,883 & 24 & 0,386 & 9,425 & 10,674 & $-12,605$ & 31,455 \\
\hline & $\begin{array}{c}\text { Variaçõe } \\
\mathrm{s} \text { iguais } \\
\text { não } \\
\text { assumida } \\
\mathrm{s}\end{array}$ & & & 0,879 & 18,997 & 0,390 & 9,425 & 10,718 & $-13,008$ & 31,858 \\
\hline \multirow[b]{2}{*}{ PROAGRO } & $\begin{array}{c}\text { Variaçõe } \\
\text { s iguais } \\
\text { assumida } \\
\text { s }\end{array}$ & 0,478 & 0,496 & $0, \overline{4} 27$ & 24 & 0,673 & $-3,150$ & 7,369 & $-18,359$ & 12,059 \\
\hline & $\begin{array}{c}\text { Variaçõe } \\
\mathrm{s} \text { iguais } \\
\text { não } \\
\text { assumida } \\
\mathrm{s}\end{array}$ & & & $0, \overline{4} 34$ & 20,242 & 0,669 & $-3,150$ & 7,253 & $-18,267$ & 11,967 \\
\hline \multirow{2}{*}{$\begin{array}{l}\text { Assistência } \\
\text { Técnica }\end{array}$} & $\begin{array}{c}\text { Variaçõe } \\
\text { s iguais } \\
\text { assumida } \\
\text { s }\end{array}$ & $\begin{array}{c}15,95 \\
6\end{array}$ & 0,001 & $\begin{array}{c}- \\
1,613\end{array}$ & 24 & 0,120 & $-4,288$ & 2,659 & $-9,774$ & 1,199 \\
\hline & $\begin{array}{c}\text { Variaçõe } \\
\mathrm{s} \text { iguais } \\
\text { não } \\
\text { assumida } \\
\mathrm{s}\end{array}$ & & & $\begin{array}{c}- \\
1,316\end{array}$ & 10,068 & 0,217 & $-4,288$ & 3,258 & $-11,541$ & 2,966 \\
\hline \multirow{2}{*}{$\begin{array}{c}\text { Juros de } \\
\text { Despesas } \\
\text { Financeiras }\end{array}$} & $\begin{array}{c}\text { Variaçõe } \\
\text { s iguais } \\
\text { assumida } \\
\text { s }\end{array}$ & 2,341 & 0,139 & $\begin{array}{c}- \\
4,183\end{array}$ & 24 & 0,000 & $-15,250$ & 3,646 & $-22,774$ & $-7,726$ \\
\hline & $\begin{array}{c}\text { Variaçõe } \\
\mathrm{s} \text { iguais } \\
\text { não } \\
\text { assumida } \\
\mathrm{s}\end{array}$ & & & $4, \overline{741}$ & 23,838 & 0,000 & $-15,250$ & 3,216 & $-21,891$ & $-8,609$ \\
\hline \multirow[b]{2}{*}{ Depreciação } & $\begin{array}{c}\text { Variaçõe } \\
\text { s iguais } \\
\text { assumida } \\
\text { s }\end{array}$ & $\begin{array}{c}26,35 \\
0\end{array}$ & 0,000 & 1,771 & 24 & 0,089 & 20,850 & 11,770 & $-3,442$ & 45,142 \\
\hline & $\begin{array}{c}\text { Variaçõe } \\
\mathrm{s} \text { iguais } \\
\text { não } \\
\text { assumida } \\
\mathrm{s}\end{array}$ & & & 1,484 & 10,825 & 0,166 & 20,850 & 14,051 & $-10,137$ & 51,837 \\
\hline
\end{tabular}

Fonte: Elaborado pelos autores.

Tabela 12. Teste $T$ de amostras independentes entre os estados do MT e PR com as variáveis de produtividade e de despesas. 


\begin{tabular}{|c|c|c|c|c|c|c|c|c|c|c|}
\hline & \multicolumn{2}{|c|}{$\begin{array}{c}\text { de } \\
\text { variações }\end{array}$} & \multirow{3}{*}{$\mathbf{t}$} & \multirow{3}{*}{$\begin{array}{c}\text { Grau } \\
\text { de } \\
\text { Liber } \\
\text { dade }\end{array}$} & \multirow{3}{*}{$\begin{array}{c}\text { Valor }-p \\
(2 \\
\text { extremidad } \\
\text { es })\end{array}$} & \multirow{3}{*}{$\begin{array}{l}\text { Difere } \\
\text { nça de } \\
\text { Média }\end{array}$} & \multirow{3}{*}{$\begin{array}{c}\text { Erro } \\
\text { padrão } \\
\text { de } \\
\text { diferenç } \\
\text { a }\end{array}$} & \multirow{2}{*}{\multicolumn{2}{|c|}{$\begin{array}{l}\text { 95\% Intervalo } \\
\text { de confiança } \\
\text { da diferença }\end{array}$}} \\
\hline & & \multirow[t]{2}{*}{$\mathbf{F}$} & \multirow{2}{*}{$\begin{array}{l}\text { Valor } \\
-\mathbf{p}\end{array}$} & & & & & & & \\
\hline & & & & & & & & & $\begin{array}{l}\text { Inferi } \\
\text { or }\end{array}$ & $\begin{array}{l}\text { Superi } \\
\text { or }\end{array}$ \\
\hline \multirow{2}{*}{$\begin{array}{l}\text { Produtivid } \\
\text { ade }\end{array}$} & $\begin{array}{c}\text { Variações iguais } \\
\text { assumidas }\end{array}$ & $\begin{array}{c}0,0 \\
59 \\
\end{array}$ & 0,810 & $\begin{array}{c}0,25 \\
8\end{array}$ & 32 & 0,798 & 0,111 & 0,431 & $-0,766$ & 0,988 \\
\hline & $\begin{array}{l}\text { Variações iguais não } \\
\text { assumidas }\end{array}$ & & & $\begin{array}{c}0,25 \\
9\end{array}$ & $\begin{array}{c}31,89 \\
1\end{array}$ & 0,797 & 0,111 & 0,429 & $-0,763$ & 0,985 \\
\hline \multirow{2}{*}{$\begin{array}{c}\text { Transport } \\
\mathrm{e}\end{array}$} & $\begin{array}{l}\text { Variações iguais } \\
\text { assumidas }\end{array}$ & $\begin{array}{l}8,7 \\
58 \\
\end{array}$ & 0,006 & $\begin{array}{c}2,65 \\
2\end{array}$ & 32 & 0,012 & 18,444 & 6,954 & 4,280 & 32,608 \\
\hline & $\begin{array}{l}\text { Variações iguais não } \\
\text { assumidas }\end{array}$ & & & $\begin{array}{c}2,77 \\
1\end{array}$ & $\begin{array}{c}22,94 \\
8\end{array}$ & 0,011 & 18,444 & 6,657 & 4,672 & 32,217 \\
\hline \multirow{2}{*}{$\begin{array}{l}\text { Armazena } \\
\text { gem }\end{array}$} & $\begin{array}{c}\text { Variações iguais } \\
\text { assumidas }\end{array}$ & $\begin{array}{l}3,2 \\
75\end{array}$ & 0,080 & $\begin{array}{c}1,70 \\
7\end{array}$ & 32 & 0,098 & 23,292 & 13,645 & $-4,503$ & 51,086 \\
\hline & $\begin{array}{c}\text { Variações iguais não } \\
\text { assumidas }\end{array}$ & & & $\begin{array}{c}1,76 \\
4\end{array}$ & $\begin{array}{c}26,77 \\
2 \\
\end{array}$ & 0,089 & 23,292 & 13,201 & $-3,805$ & 50,388 \\
\hline \multirow{2}{*}{$\begin{array}{l}\text { PROAGR } \\
\text { O }\end{array}$} & $\begin{array}{l}\text { Variações iguais } \\
\text { assumidas }\end{array}$ & $\begin{array}{l}3,0 \\
08\end{array}$ & 0,092 & $\begin{array}{c}0,90 \\
2\end{array}$ & 32 & 0,374 & 5,417 & 6,005 & $-6,816$ & 17,649 \\
\hline & $\begin{array}{l}\text { Variações iguais não } \\
\text { assumidas }\end{array}$ & & & $\begin{array}{c}0,89 \\
5 \\
\end{array}$ & $\begin{array}{c}30,00 \\
7 \\
\end{array}$ & 0,378 & 5,417 & 6,055 & $-6,950$ & 17,783 \\
\hline \multirow{2}{*}{$\begin{array}{l}\text { Assistênci } \\
\text { a Técnica }\end{array}$} & $\begin{array}{l}\text { Variações iguais } \\
\text { assumidas }\end{array}$ & $\begin{array}{l}5,0 \\
46\end{array}$ & 0,032 & $\begin{array}{c}- \\
0,67 \\
5\end{array}$ & 32 & 0,504 & $-1,465$ & 2,170 & $-5,886$ & 2,955 \\
\hline & $\begin{array}{c}\text { Variações iguais não } \\
\text { assumidas }\end{array}$ & & & $\begin{array}{c}0,70 \\
7 \\
\end{array}$ & $\begin{array}{c}22,19 \\
6\end{array}$ & 0,487 & $-1,465$ & 2,073 & $-5,763$ & 2,832 \\
\hline \multirow{2}{*}{$\begin{array}{c}\text { Juros de } \\
\text { Despesas } \\
\text { Financeira } \\
\text { s }\end{array}$} & $\begin{array}{l}\text { Variações iguais } \\
\text { assumidas }\end{array}$ & $\begin{array}{l}4,8 \\
15\end{array}$ & 0,036 & $\begin{array}{c}- \\
4,50 \\
4\end{array}$ & 32 & 0,000 & 12,694 & 2,819 & $\begin{array}{c}- \\
18,436\end{array}$ & $-6,953$ \\
\hline & $\begin{array}{c}\text { Variações iguais não } \\
\text { assumidas }\end{array}$ & & & $\begin{array}{c}- \\
4,34 \\
9 \\
\end{array}$ & $\begin{array}{c}21,91 \\
4\end{array}$ & 0,000 & 12,694 & 2,919 & 18,750 & $-6,639$ \\
\hline \multirow{2}{*}{$\begin{array}{l}\text { Depreciaç } \\
\text { ão }\end{array}$} & $\begin{array}{c}\text { Variações iguais } \\
\text { assumidas }\end{array}$ & $\begin{array}{l}5,2 \\
52\end{array}$ & 0,029 & $\begin{array}{c}2,89 \\
4\end{array}$ & 32 & 0,007 & 44,583 & 15,403 & 13,208 & 75,958 \\
\hline & $\begin{array}{l}\text { Variações iguais não } \\
\text { assumidas }\end{array}$ & & & $\begin{array}{c}3,04 \\
7\end{array}$ & $\begin{array}{c}20,06 \\
4\end{array}$ & 0,006 & 44,583 & 14,630 & 14,072 & 75,094 \\
\hline
\end{tabular}

Fonte: Elaborado pelos autores. 


\section{ANEXO III (Não disponibilizar aos alunos/participantes)}

\section{NOTAS DE ENSINO}

\section{Objetivos educacionais:}

Promover a utilização da interdisciplinaridade na área de negócios para a tomada de decisão, nesse caso, trabalhar de forma integrada com disciplinas de Contabilidade, Administração e afins e Métodos Quantitativos (Estatística). A interdisciplinaridade penetrou nas ciências (ciências sociais e humanidade), sendo atualmente um tema muito discutido e de grande interesse, pois, é foco de investigação para o avanço do conhecimento (PALMER, 2007).

Turner (1991) aborda que as ideias inovadoras, na grande maioria das vezes, vêm de estudos interdisciplinares. O autor complementa, apontando a relevância da inserção da interdisciplinaridade no processo ensino-aprendizagem, o que possibilitará tanto aos alunos quanto aos professores romperem as fronteiras das disciplinas e formarem um conhecimento completo e globalizado, por meio da interação entre os conteúdos aprendidos e seus desdobramentos nas diversas áreas de conhecimento.

Nesse sentido, Silva e Pinto (2009) apontam a necessidade de organização curricular que privilegie a interdisciplinaridade, pois os saberes exigidos pelo cenário mundial do campo de trabalho não combinam com a fragmentação do conhecimento no que se refere à organização com disciplinas isoladas que não interagem entre si.

\section{Recomendações para aplicação do caso:}

Recomenda-se a aplicação deste caso em cursos de graduação e pós-graduação na área de negócios: Administração; Ciências Contábeis; Economia, dentre outros. Em relação às disciplinas, o caso proposto poderá ser trabalhado nas áreas de Contabilidade de Custos e Métodos Quantitativos, privilegiando a interdisciplinaridade entre os conteúdos abordados nessas duas áreas do conhecimento.

\section{Impactos proporcionados pelo caso:}

- Integrar os elementos de análise de custos relacionados ao agronegócio com ferramentas de métodos quantitativos, com o objetivo de garantir a assertividade no processo de tomada de decisão.

- Permitir aos leitores a experiência de trabalhar com dilemas envolvendo o setor de agronegócios, bem como conhecer as variáveis de custos e despesas consumidos nesse processo de produção. 
- Fomentar discussões sobre diferentes perspectivas e interpretações da problemática proposta, para que os leitores possam identificar outras possibilidades de resolução para o caso.

- Promover a interdisciplinaridade, trabalhando conteúdos da área de custos e métodos quantitativos para a resolução do problema proposto.

\section{Elementos tratados no caso}

- Elementos de custos e despesas no agronegócio;

- Diversificação de investimentos;

- Estratégia Empresarial;

- Diferentes tipos de commodities comercializadas no mercado brasileiro;

- A interdisciplinaridade na área de custos e aplicação de métodos quantitativos no ambiente empresarial como ferramenta importante para tomada de decisão assertiva;

- A utilização de softwares específicos que permitem a aplicação de testes estatísticos para tratamento dos dados e geração de resultados;

\section{Dilemas apresentados aos alunos:}

Conforme apresentado no tópico 6 (Desafio do Caso), seguem as questões que poderão ser trabalhadas pelos professores para a resolução e discussão do caso:

1) Como se dá o comportamento dos custos e das despesas em GO, PR e MT? Existe diferença perceptível nas respectivas composições nesses estados? Explique.

2) Quais estados, entre PR, MT ou GO, possuem logísticas mais favoráveis para a escoação da produção de acordo com a infraestrutura física que a empresa já possui? Explique.

3) Em qual estado a GRAN Agro deve iniciar seu negócio no ramo do milho? Levando em consideração todo o contexto, quais as melhores possibilidades de geração de receitas com menores despesas e custos? Explique.

\section{Etapas para Aplicação do Caso:}

Propõe-se a aplicação deste caso em grupos, dando-se a formação desses grupos com a participação de, no máximo, cinco alunos. A aplicação em sala de aula envolverá cinco etapas. Dependendo do tempo disponibilizado para as disciplinas, serão utilizados dois encontros.

1'etapa: solicitar a leitura prévia dos alunos, tendo esses, em sala de aula (em grupos), 30 minutos para discussões iniciais sobre a resolução do caso;

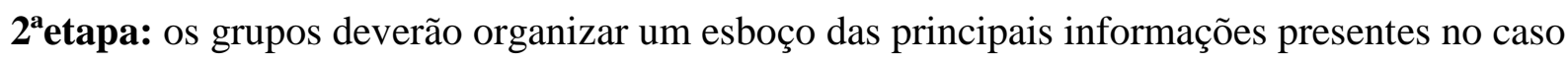
(custos e o setor de agronegócios no Brasil e Base de dados de agronegócios), em tempo aproximado de 20 minutos; 


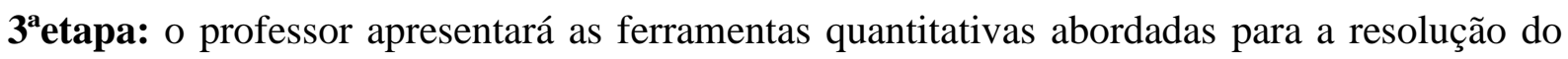
caso (tempo estimado: 20 minutos);

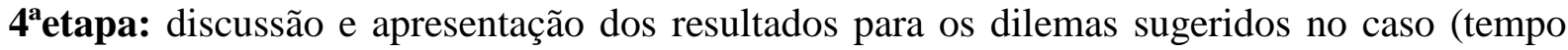
estimado: 50 minutos) e

5 etapa: considerações do professor sobre os resultados e discussões apresentadas (tempo estimado: 15 minutos).

Por se tratar de um caso que reúne conteúdos interdisciplinares, o tempo estimado para a sua aplicação poderá variar. Assim, o professor (ou professores) que for (em) aplicá-lo poderá adaptar o caso, considerando os objetivos pedagógicos propostos.

\section{Resolução do caso:}

Questão 1: Como se dá o comportamento dos custos e das despesas em GO, PR e MT? Existe diferença perceptível nas respectivas composições nesses estados? Explique.

Possibilidade de Resposta: Deverão ser disponibilizados aos alunos os Anexo I do caso composto pelas seguintes tabelas: analise descritiva da cultura do milho safrinha, correlação linear de Pearson e Anexo II com o Teste t de amostras independentes, considerando os estados pesquisados (GO, PR e MT). Os alunos devem realizar análises completas, apresentando o comportamento dos custos e das despesas para os estados do GO, PR e MT, bem como apresentar as possíveis interpretações que podem ser retiradas das análises dos dados.

Uma informação importante para a solução do caso é a correta utilização das técnicas estatísticas disponibilizadas nas tabelas em Anexos a fim de gerar respostas precisas e suficientes para a solução da problemática apresentada. No Brasil, existem diversas entidades que realizam a compilação dos dados referentes aos custos de produção e precificação. Assim, o professor poderá indicar aos alunos diferentes bases de dados relativas ao agronegócio no Brasil disponíveis na internet. Importante lembrar que, para este caso específico, o professor deve enfatizar o uso dos dados da CONAB. O comportamento das despesas e dos custos possuem diferenças perceptíveis quando são analisados os gastos que compõem cada estado, conforme dispostos nos Anexos I e II.

Questão 1 - Letra A (Análise Descritiva - Tabelas 3 e 4): Analisar o comportamento das variáveis nos três estados: MT, GO, PR de acordo com a análise descritiva (Tabelas 3 e 4). Levando em consideração somente a Variável Aluguel de Máquinas e seu respectivo coeficiente de variação é possível perceber algum ponto fraco em algum estado? Explique. Possibilidade de Resposta: O Anexo I contém as Tabelas 3 e 4 que trazem as análises descritivas geral de cada variável e por estado (PR, GO e MT). A descritiva de um conjunto de dados é sempre o ponto inicial de análise quando se utilizam procedimentos estatísticos, primordialmente, é necessário conhecer o comportamento das variáveis que compõem o banco de dados que será manipulado. As medidas mais utilizadas em estatística descritiva têm 
como foco principal aprofundar o estudo do comportamento das variáveis em relação a valores centrais, dispersões ou às formas de distribuição ao redor da média (FÁVERO et al, 2009).

Quando comparados o Mato Grosso e o Goiás (Tabela 4), torna-se possível perceber que o estado do Mato Grosso possui 6 maiores médias nas variáveis analisadas (fertilizantes, 406,7; defensivos, 154,6; manutenção de máquinas, 40,2; armazenagem, 109,6; PROAGRO, 28,7; e depreciação, 159,8). Em contrapartida, o estado do Goiás apresenta as 5 maiores médias em outras variáveis: (sementes, 232,6; produtividade, 4,9; máquinas, 184,9; mão de obra temporária, 11,2; e transporte, 104,0). De maneira geral, o estado do Goiás possui os maiores coeficientes de variação, mas, para saber se existe diferença significativa nos custos e despesas entre os estados, é necessário analisar os resultados do Teste $t$ de diferença de médias (Tabelas 7 a 12).

Na variável aluguel de máquinas, no Goiás existem $301 \%$ de percentual de variabilidade do coeficiente de variação na composição da média do estado (C.V.\%), que é sinônimo de variação de Pearson ([desvio padrão/média] x 100). A variação verificada no Goiás mostra um ponto frágil que é a necessidade de alugar máquinas para colher sua produção. Sabendo disso, a GRAN Agro pode preferir comprar o milho do Mato Grosso, que tem $0 \%$ de variabilidade na composição da média desse custo no estado se levasse em conta somente esse critério para análise, pois essa variável também pode evidenciar que o estado do Mato Grosso é mais preparado e equipado tecnologicamente.

Os menores valores das médias e dos coeficientes de variação evidenciam o comportamento dos custos e das despesas no estado do Paraná, mostrando que essa composição de gastos é mais similar nesse estado, visto que apresentam valores mais homogêneos.

Na Tabela 3, se comparados os valores máximos e mínimos, percebe-se uma alta amplitude total para variável fertilizante em todas as produções, portanto, ao longo do período em análise, houve um crescimento na utilização de fertilizante. Como os dados referem-se à safrinha, período de plantação extemporânea, é necessário um incremento da qualidade da terra, permitindo uma produção final com maior qualidade essa é uma possível análise.

$\mathrm{Na}$ Tabela 3, as médias que apresentaram maiores magnitudes foram as variáveis fertilizantes e sementes, enquanto que os menores foram produtividade e mão de obra temporária.

Ainda na Tabela 3 nota-se que a variável aluguel de máquinas apresentou maior coeficiente de variação entre as variáveis em análise, o que foi influenciado pela alta variação encontrada no estado do Goiás nessa variável. No geral, as variáveis que apresentam maior homogeneidade dos dados entre os estados, ao longo dos anos, foram juros de despesas financeiras, transportes, máquinas e fertilizantes, com coeficientes de variação de 27\%, 29\%, 30\% e 30\%, respectivamente.

Questão 1 - Letra B (Correlação Linear de Pearson - Tabelas 5 e 6): Na Tabela 5 a maior associação negativa linear foi apresentada entre as variáveis produtividade e manutenção de 
máquinas como pode ser interpretada essa situação na prática? Ainda analisando a Tabela 5 qual a maior associação positiva linear e qual a interpretação que pode ser feita? E na Tabela 6 quais as maiores associações lineares negativas e positivas? Possibilidade de Resposta: Para a construção das Tabelas 5 e 6 (correlação linear de Pearson dos custos e das despesas), considerou-se que as distribuições de todas as variáveis são normais, permitindo o uso do coeficiente de correlação de Pearson para ser trabalhada a interpretação dos resultados com os alunos.Em estudos que envolvem duas ou mais variáveis, é comum e necessário conhecer o padrão de associação entre as variáveis, portanto, após a análise descritiva, o próximo passo consiste em analisar o coeficiente de correlação entre todas variáveis de custos e despesas do milho safrinha.

A correlação é uma medida da variância compartilhada, analisada de maneira linear. O coeficiente de correlação linear de Pearson (r) e o coeficiente (rho) de correlação linear de Spearman são análises de correlação parcial das matrizes de correlação, ou seja, o cálculo da correlação é feito em pares de variáveis $(\mathrm{X}, \mathrm{Y})$ dispostas em uma matriz, e os respectivos valores expressos expõem o coeficiente de correlação, que é a mensuração da força de associação entre as variáveis (LIRA, 2004).

O coeficiente é um valor que pode ser compreendido no intervalo $-1 \leq \mathrm{e}+\leq 1$ o valor expresso absoluto indica a força de relacionamento das variáveis, onde: -1 expressa uma correlação linear negativa perfeita; +1 expressa uma correlação linear positiva; e 0 , quando não há correlação linear entre as duas variáveis (LIRA, 2004).

Nas Tabelas 5 e 6, consta a análise de correlação linear de Pearson das variáveis de custos e despesas e a variável produtividade. Abaixo da diagonal principal, estão os valores referentes aos coeficientes da correlação linear de Pearson e, acima da diagonal principal, estão os respectivos valores de $p$.

Como exemplo de interpretação de resultado, na Tabela 5, a maior associação negativa linear foi apresentada entre as variáveis produtividade e manutenção de máquinas. Isso quer dizer que, quanto maior a produtividade, menor a manutenção de máquinas, ou seja, elas são inversamente proporcionais. Já a maior associação positiva linear aconteceu entre máquinas e manutenção de máquinas, ou seja, os gastos são diretamente proporcionais; assim, quanto mais horas as máquinas trabalharem, maiores serão os gastos com a sua manutenção.

É importante destacar que, nas Tabelas 5 e 6, nota-se que elas possuem legendas com as variáveis significativas com nível nominal de significância de $1 \%$ e de $5 \%$. Quando a variável não é significativa, o resultado da correlação linear de Pearson e do Teste t aplica-se somente aos dados desta pesquisa, porém, quando os valores são significativos, os resultados do Teste t de diferença de médias e da correlação linear de Pearson podem ser extrapolados para a população, fazendo assim uma inferência sobre as variáveis analisadas.

Questão 1 - Letra C (Teste t de diferença de médias - Tabelas 7 a 12): As médias diferentes de custos e despesas em cada estado (MT, GO e PR) são decorrência do acaso ou são estatisticamente 
diferentes? Responda baseando-se nas tabelas disponibilizadas do Teste $\mathrm{T}$ (Tabelas 7 a 12). Possibilidade de Resposta: As Tabelas 7 a 12 contêm os resultados dos Testes t de diferença de médias de custos e de despesas separados e comparando os estados entre si, dois a dois.

O Teste t de Student é utilizado para comparação de médias. A média como análise descritiva de uma população é uma das características mais importantes quando a distribuição dos dados é normal (HAIR et al 2009).

O Teste $\mathrm{t}$ tem duas pressuposições (BUSSAB; MORETTIN 2003):

$1^{\circ}$ ) Os dados precisam ter distribuição aproximadamente normal (neste estudo, considera-se que tenham);

$2^{\circ}$ ) As variâncias populacionais das duas populações devem ser iguais a um nível nominal de significância de 5\%. (É verificada a homogeneidade das variâncias no Teste Levene com H0: Variâncias Homogêneas)

Primeiramente, analisa-se se as variâncias são iguais, para posteriormente prosseguir com o Teste de diferença de média, neste caso sugere-se o Teste t de hipóteses de amostras independente, conforme ilustrado nas Equações (1) e (2) (BUSSAB; MORETTIN 2003):

$$
\begin{array}{ll}
\mathrm{H} 0: \mu 1=\mu 2 & \text { Equação (1) } \\
\mathrm{H} 1: \mu 1 \neq \mu 2 & \text { Equação (2) }
\end{array}
$$

Onde: $\mu$ : média populacional.

O teste utilizado nesta pesquisa é o bilateral, o qual, na região de rejeição, se distribui igualmente em ambas as caudas da distribuição. Esse teste serve para mostrar que um parâmetro é significativamente diferente de um determinado valor, e pressupõe-se para todas as tabelas de Teste t um nível nominal de significância de 5\% (BUSSAB; MORETTIN 2003). Quando, no intervalo de confiança, o zero estiver presente, há igualdade entre as médias ou, ao verificar o valor de $p$ do Teste t e ele for menor que o nível nominal de significância de $5 \%$, não há igualdade de médias, ou seja, quando o valor de $p$ é maior que o nível nominal de significância de 5\%, existe diferença nas médias dos grupos

\begin{tabular}{|c|c|c|c|}
\hline $\begin{array}{c}\text { TESTE T DE } \\
\text { DIFERENÇA } \\
\text { DE MÉDIA }\end{array}$ & $\begin{array}{c}\text { NÃO POSSUEM } \\
\text { HOMOGENEIDADE DAS } \\
\text { VARIÂNCIAS E, PORTANTO A } \\
\text { ANÁLISE NÃO PODE } \\
\text { PROSSEGUIR. } \\
\text { (o valor de } p \text { no teste do Levene é } \\
\text { inferior a } 0,05, \text { portanto, não há } \\
\text { homogeneidade das variâncias e não é }\end{array}$ & $\begin{array}{l}\text { (Os valores de } p \text { do teste } \mathrm{T} \text { foram } \\
\text { acima de } 5 \% \text { e em todos os } \\
\text { intervalos o zero estava presente) }\end{array}$ & $\begin{array}{l}\text { (O valor de } p \text { é inferior } \\
\text { a } 5 \% \text {, portanto, rejeita- } \\
\text { se a H0 e aceita a H1 } \\
\text { como verdadeira) }\end{array}$ \\
\hline
\end{tabular}
(BUSSAB; MORETTIN 2003).

No quadro 2 segue explicação de todos os Testes t de diferença de média das Tabelas 7 a 12.

Quadro 2: Interpretação dos Teste t de diferenças de médias das Tabelas 7 a 12. 


\begin{tabular}{|c|c|c|c|}
\hline & $\begin{array}{l}\text { possível prosseguir com a análise do } \\
\text { teste T somente para essas variáveis, } \\
\text { para as demais é possível). }\end{array}$ & & \\
\hline $\begin{array}{l}\text { (Tabela 7) } \\
\text { Custos entre } \\
\text { GO e PR }\end{array}$ & Máquinas e fertilizantes. & $\begin{array}{c}\text { Aluguel de Máquinas }(0,163), \\
\text { Mão de Obra Temporária } \\
(0,130), \text { Mão de obra fixa } \\
(0,518), \text { Sementes }(0,492), \\
\text { Defensivos }(0,060) \text { e manutenção } \\
\text { de máquinas }(0,590) .\end{array}$ & Produtividade $(0,02)$. \\
\hline $\begin{array}{l}\text { (Tabela 8) } \\
\text { Custos entre } \\
\text { GO e MT }\end{array}$ & Máquinas e aluguel de máquinas. & $\begin{array}{l}\text { Mão de obra temporária, } \\
\text { sementes, fertilizantes, } \\
\text { manutenção de máquinas. }\end{array}$ & $\begin{array}{l}\text { Produtividade, mão de } \\
\text { obra fixa e defensivos. }\end{array}$ \\
\hline $\begin{array}{l}\text { (Tabela 9) } \\
\text { Custos MT e } \\
\text { PR }\end{array}$ & $\begin{array}{l}\text { Aluguel de máquinas, mão de obra fixa } \\
\text { e manutenção de máquinas. }\end{array}$ & $\begin{array}{l}\text { Produtividade, máquinas, mão de } \\
\text { obra temporária, mão de obra } \\
\text { fixa, sementes e defensivos. }\end{array}$ & $\begin{array}{l}\text { Fertilizantes e } \\
\text { manutenção de } \\
\text { máquinas. }\end{array}$ \\
\hline $\begin{array}{l}\text { (Tabela 10) } \\
\text { Despesas entre } \\
\text { GO e MT }\end{array}$ & $\begin{array}{l}\text { Analisando-a é possível verificar que } \\
\text { todas variáveis possuem p-valor no teste } \\
\text { de Levene acima de } 5 \% \text { do valor } \\
\text { nominal de significância, pode-se } \\
\text { prosseguir com o teste para todas } \\
\text { variáveis, pois todas são homogêneas. }\end{array}$ & $\begin{array}{c}\text { Transporte, armazenagem, } \\
\text { PROAGRO, assistência técnica, } \\
\text { juros de despesas financeiras e } \\
\text { depreciação. }\end{array}$ & Produtividade. \\
\hline $\begin{array}{l}\text { (Tabela 11) } \\
\text { Despesas entre } \\
\text { GO e PR }\end{array}$ & $\begin{array}{c}\text { Transporte, assistência técnica e } \\
\text { depreciação. }\end{array}$ & Armazenagem e PROAGRO. & $\begin{array}{l}\text { Produtividade, } \\
\text { assistência técnica e } \\
\text { juros de despesas } \\
\text { financeiras. }\end{array}$ \\
\hline $\begin{array}{c}\text { (Tabela 12) } \\
\text { Despesas entre } \\
\text { MT e PR }\end{array}$ & $\begin{array}{l}\text { Transporte, Assistência técnica, Juros de } \\
\text { despesas financeiras e depreciação. }\end{array}$ & $\begin{array}{c}\text { Produtividade, armazenagem e } \\
\text { PROAGRO. }\end{array}$ & Nenhuma. \\
\hline
\end{tabular}

Fonte: Elaborado pelos autores.

A média possui características importantes de uma variável para comparar os pares com a finalidade de determinar se existe ou não diferenças significativas. Portanto esse tipo de análise realizada no Quadro 2 é necessário, pois a média é uma das características mais importantes de uma variável e comparar os pares pra conhecer se existe ou não diferença entre os pares é importante, pois se assim não o fizer corre-se o risco de afirmar como igual coisas que são diferentes.

Questão 2: Quais estados, entre PR, MT ou GO, possuem logísticas mais favoráveis para a escoação da produção de acordo com a infraestrutura física que a empresa já possui? Levando em consideração o caso relatado e seus conhecimentos sobre transportes logísticos. 
Possibilidade de Resposta: Em relação ao cenário e infraestrutura atual da GRAN Agro, a empresa possui armazéns no estado de MG e na região de MATOPIBA - área situada na divisa dos estados do Maranhão, Tocantins, Piauí e Bahia. A participação da empresa no mercado é de cerca 25\% (região considerada como a nova fronteira agrícola do país). Os estados mais próximos estrategicamente a essas regiões são os estados de GO e MT, que podem utilizar estruturas ferroviárias (ferrovia NorteSul) e os corredores multimodais do Arco Norte do País nos estados do Mato Grosso, Rondônia, Amazonas, Tocantins e Maranhão.

Para essa questão, o professor pode considerar aspectos específicos de logística que sejam peculiares à época em que o caso esteja sendo trabalhado, utilizando-se como base de informações as estruturas das malhas rodoviária, ferroviária e hidroviária do país e desses estados para escoamento da produção.

O professor tem a opção de explicar as diferenças de modais de transportes e as diferenças dos valores que compõem o valor final para transportar mercadorias. No site do Departamento Nacional de Infraestrutura de Transportes - DNIT, é possível encontrar essas informações na fonte oficial do Brasil dentro do espaço modais (DNIT, 2002).

Questão 3: Em qual estado a GRAN Agro deve iniciar seu negócio no ramo do milho? Levando em consideração todo o contexto, quais as melhores possibilidades de geração de receitas com menores despesas e custos? Para responder essa questão utilize a lógica das respostas nas questões anteriores (Questão 1 Letras: A, B, C e Questão 2).

Possibilidade de Resposta: A resposta da questão número 2 é levada em consideração para afunilar as possíveis escolhas. Como os estados do GO e MT são as regiões estratégicas de acordo com a infraestrutura existente da empresa em virtude da logística, e analisando as Tabelas nos Anexos I e II, exclui-se das alternativas possíveis o estado do Paraná para comercialização inicial do milho safrinha.

O Paraná possui os menores valores de custos e despesas dentre os estados analisados. No Paraná, a média de produção do estado é inferior, e a empresa teria margem maior pra negociar o valor do produto, pois o produtor tem gastos menores. Quando a GRAN Agro considera a logística de acordo com o local da infraestrutura que a empresa possui, é inviável a comercialização com o Paraná por ser tratar da maior distância para o transporte do grão adquirido, e levando em consideração que o valor percentual com os meios de transporte, são os gastos com valores mais elevados na composição das despesas quando se comercializam grãos.

O professor deve analisar que a variável de transporte utilizada no estudo não é o valor do transporte do grão até o cliente. A variável, segundo a CONAB, tem a seguinte descrição: transporte - são as 
despesas de transporte do produto da propriedade rural até a estrutura de limpeza e secagem (conforme Tabela 2, Anexo I).

A GRAN Agro deve iniciar suas operações em Goiás, comprando o milho daquele estado, pois, de maneira geral, é esse estado que possui os menores custos de produção, conforme descritiva (Tabelas 3 e 4). Além disso, existe diferença significativa na composição dos custos conforme demonstrado no Quadro 2 (Tabelas 8), as médias são diferentes nas variáveisfertilizantes e manutenção de máquinas, sendo os valores inferiores no estado do Goiás se comparados aos do Mato Grosso. Quanto às demais variáveis, essas não possuem diferença de média.

Ainda comparando Mato Grosso e Goiás, quanto às despesas, conforme a Tabela 10 (analisado no Quadro 2), não há diferença de média entre esses estados. Há diferença apenas na produtividade, sendo Goiás o estado mais produtivo do país, novamente, um ponto positivo.

Portanto, a empresa deve investir inicialmente no estado do Goiás, pois aquele é o estado mais próximo da infraestrutura existente da empresa GRAN Agro. Assim sendo, os custos com transporte serão menores, devendo-se essa escolha ainda ao fato de que, entre GO e MT, que estão próximos à infraestrutura da empresa e, também, pelo fato de o estado de Goiás se destacar em relação aos menores custos de produção. Além disso, a sua produtividade é superior, portanto o estado é mais eficiente em sua produção se comparados o comportamento dos custos e as despesas, as quais possuem igualdade nas médias.

O professor pode dizer aos alunos que existe a possibilidade de o gestor verificar a viabilidade de estabelecer relações com o estado do Paraná, pois ele apresenta, de maneira geral, os menores custos de produção e as menores despesas e a menores variabilidades desses valores. O gestor da GRAN Agro pode solicitar ao PR desconto por meio de possível parceria com a finalidade de verificar se um possível desconto possível cobre os custos de transporte do produto, podendo essa ser uma alternativa futura. 